\title{
Inflammation-induced Gro1 triggers senescence in neuronal progenitors: effects of estradiol
}

Svetlana Zonis ${ }^{1}$, Joshua J. Breunig ${ }^{2}$, Adam Mamelak ${ }^{1,2}$, Kolja Wawrowsky $^{3}$, Catherine Bresee ${ }^{4}$, Nadiya Ginzburg ${ }^{1}$ and Vera Chesnokova ${ }^{1 *}$ (i)

\begin{abstract}
Background: Inflammation has been proposed to contribute to the decline in adult hippocampal neurogenesis. Proinflammatory cytokines activate transcription of chemokine growth-regulated oncogene a (Gro1) in human and murine hippocampal neuronal progenitor cells (NPC). The goal of this study was to investigate the effects of Gro1 on hippocampal neurogenesis in the presence of inflammation.

Methods: Human hippocampal NPC were transfected with lentivirus expressing Gro1, and murine NPC and hippocampal neuronal HT-22 cells were treated with Gro1 protein. A plasmid expressing mGro1 was electroporated in the hippocampus of newborn mice that were sacrificed 10 days later. Adult male and female mice were injected with lipopolysaccharide (LPS; $1 \mathrm{mg} / \mathrm{kg}$, i.p in five daily injections) or normal saline. Adult male mice were implanted with pellets releasing 17- $\beta$ estradiol (E2; $2.5 \mathrm{mg} /$ pellet, $41.666 \mu \mathrm{g} /$ day release) or placebo for 6 weeks and challenged with LPS or normal saline as above. In both experiments, mice were sacrificed $3 \mathrm{~h}$ after the last injection. Hippocampal markers of neurogenesis were assessed in vitro and in vivo by Western blot, real-time PCR, and immunohisto/cytochemistry.
\end{abstract}

Results: Gro1 induced premature senescence in NPC and HT-22 cells, activating senescence-associated $\beta$-galactosidase and the cell cycle inhibitor p16 and suppressing neuroblast proliferation and expression of doublecortin (DCX) and neuron-specific class III beta-tubulin (Tuj-1), both neuroblast markers, while promoting proliferation of neural glial antigen 2 ( $\mathrm{Ng} 2$ )-positive oligodendrocytes. Gro1 overexpression in the hippocampus of newborn mice resulted in decreased neuroblast development, as evidenced by decreased DCX expression and increased expression of plateletderived growth factor a receptor (PDGFaR), a marker of oligodendrocyte precursors. In adult mice, Gro1 was induced in response to LPS treatment in male but not in female hippocampus, with a subsequent decrease in neurogenesis and activation of oligodendrocyte progenitors. No changes in neurogenesis were observed in females. Treatment with E2 blunted LPS-induced Gro1 in the male hippocampus.

Conclusions: Inflammation-induced Gro1 triggers neuroblast senescence, thus suppressing new neuron development in the hippocampus. Sex-dependent differences in Gro1 response are attributed to estradiol, which blunts these changes, protecting the female hippocampus from the deleterious effects of inflammation-induced Gro1 on neurogenesis.

Keywords: Chemokines, Gro1, Hippocampus, Neuronal progenitor cells, Senescence, LPS-induced inflammation, Sex dimorphism

\footnotetext{
* Correspondence: Chesnokovav@cshs.org

${ }^{1}$ Pituitary Center, Department of Medicine, Cedars-Sinai Medical Center, 8700

Beverly Blvd., Los Angeles, CA 90048, USA

Full list of author information is available at the end of the article
}

(c) The Author(s). 2018 Open Access This article is distributed under the terms of the Creative Commons Attribution 4.0 International License (http://creativecommons.org/licenses/by/4.0/), which permits unrestricted use, distribution, and reproduction in any medium, provided you give appropriate credit to the original author(s) and the source, provide a link to the Creative Commons license, and indicate if changes were made. The Creative Commons Public Domain Dedication waiver (http://creativecommons.org/publicdomain/zero/1.0/) applies to the data made available in this article, unless otherwise stated. 


\section{Background}

The subgranular zone (SGZ) of the hippocampus maintains the capacity for neurogenesis throughout life $[1,2]$. Radial glia-like quiescent neural stem cells express nestin or/and sex-determining region Y-box 2 (Sox2) as well as glial fibrillary acidic protein (GFAP), which, in turn, give rise to proliferating amplifying neuronal progenitors $[3,4]$. In a process of differentiation, cells committed to a neuronal lineage lose these markers and acquire markers associated with immature neurons or neuroblasts, such as doublecortin (DCX), neuron-specific class III $\beta$-tubulin (recognized by Tuj-1 antibody), and polysialylated-neural cell adhesion molecule (PSA-NCAM). In vitro, most hippocampal progenitors become neurons; therefore, hippocampal neural stem cells are typically referred to as "neuronal progenitor cells" (NPC) [2, 5]. However, in vivo, $\sim 25 \%$ of NPC differentiate into glial cells, comprising astrocytes and oligodendrocytes, and express cell-specific markers [4]. Astrocytes express the glial fibrillary acidic protein (GFAP) and S100 calciumbinding protein B (S100 $\beta$ ) [4]. Oligodendrocyte precursors express platelet-derived growth factor $\alpha$ receptor (PDGF $\alpha \mathrm{R})$, neural glial antigen $2(\mathrm{Ng} 2)$, and oligodendrocyte transcription factor 1 (Olig1) and Olig2, while mature oligodendrocytes lose these markers and begin to express O4 [6]. Over time, these newly added neurons incorporate into the functional hippocampal circuitry.

In animal models, abnormal hippocampal neurogenesis has been attributed to cognitive impairment, spatial memory, and learning deficits [7], and its potential role in depression $[8,9]$ has been widely discussed. Little is known about the role of neurogenesis in the normal adult human hippocampus, despite studies showing the presence of hippocampal neurogenesis in both human and primate adult brain [10-13]. Low proliferation capacity of human hippocampal NPC isolated from surgically removed specimens correlates with memory dysfunction in these patients [14], and antidepressant treatment significantly increases NPC in both murine and human hippocampus $[8,15,16]$, suggesting that changes in NPC can have functional consequences in adult humans as well.

It has been shown that inflammation contributes to the decline in adult hippocampal neurogenesis [17-19]. Microglial cells, which are resident macrophages in the central nervous system (CNS), respond to signals from the peripheral immune system or to local insults, inducing neuroinflammation and releasing proinflammatory cytokines [20]. Thus, mice treated with bacterial endotoxin lipopolysaccharide (LPS) mimicking acute and intensive systemic inflammation demonstrate upregulation of multiple proinflammatory cytokines that can negatively affect hippocampal neurogenesis [18, 21-23].
Chemokines are induced in astrocytes and activated microglia in response to injury [24, 25], attract immune cells to sites of tissue damage, and enhance the inflammatory response by inducing the release of inflammatory cytokines and chemokines by neutrophils [26].

Chemokine growth-regulated oncogene $\alpha$ Gro1, also known as C-X-C motif ligand (CXCL) 1 or keratinocytederived chemokine $(\mathrm{KC})$, signals through $\mathrm{G}$ proteincoupled receptor $\mathrm{CXC}$ receptor 2 (CXCR2); the human ortholog of Gro1 is interleukin (IL)-8, or CXCL8. (Both human CXCL8 and murine CXCL1 protein are here referred to as Gro1.) Gro1 is expressed in neurons and endothelial cells during status epilepticus in rats [27] and in mice after inflammatory stimuli in both endothelial cells and astrocytes [28-32]. In humans, Gro1 is induced in the brains of sepsis patients [33]. In vitro, cytokines interleukin (IL)-1 $\beta$ and tumor necrosis factor $\alpha$ (TNF $\alpha$ ) induce Gro1 in murine astrocytes [34] and neuronal precursors [35].

Gro1 transcription is regulated by nuclear factor kappa-light-chain-enhancer of activated B cells ( $\left.\mathrm{NF}_{\kappa} \mathrm{B}\right)$ transcription factor, which, in turn, is activated by proinflammatory cytokines such as IL-1 $\beta$, IL-6, and TNF $\alpha$. NFkB-dependent Gro1 induction has been observed in multiple cell types, including neurons [36], pancreatic $\beta$ cells [37], and a melanoma cell line [38].

Chemokines and their receptors are also expressed in the normal brain that is free of inflammation [39]. CXCR2 is constitutively expressed in NPC [40], and Gro1 and CXCR2 are involved in spatial and temporal regulation of oligodendrocyte proliferation in the spinal cord [41, 42] and promote oligodendrocyte maturation of neuronal stem cells [35]. Of note, Gro1 acts synergistically with PDGF expressed in astrocytes and neurons [41], stimulating proliferation of PDGF $\alpha$ R-positive oligodendrocyte progenitors and arresting their migration [43, 44].

Very little is known about the role of Gro1 in hippocampal neurogenesis. Here, we describe the effects of Gro1 on adult hippocampal human and murine NPC and on the HT-22 murine hippocampal neuronal cell line. We show that Gro1 activated the senescence pathway, as evidenced by induction of senescence-associated $\beta$-galactosidase (SA- $\beta$ gal) and the cell cycle suppressing protein $\mathrm{p} 16$, and was associated with decreased expression of Ki67, a marker of proliferation. High Gro1 negatively affected neuronal lineage, decreasing proliferation of neuroblasts positive for Tuj-1 and DCX. Similar results were obtained in vivo, where electroporation of plasmid expressing Gro1 in the hippocampus of newborn mice led to decreased DCX expression, while PDGF $\alpha$ R was elevated.

We also show that Gro1 response to systemic inflammation is sex-dependent. Intraperitoneal injection of lipopolysaccharide (LPS) induced Gro1 expression in the 
male hippocampus, but the response was blunted in females, and treatment with $17-\beta$ estradiol (E2) reduced LPS-triggered Gro1 expression in male mice.

These findings outline new mechanisms underlying aberrant hippocampal neurogenesis and suggest a previously unknown sex-specific influence of Gro1 on neurogenesis during inflammation. These findings may be linked to age- and sex-specific differences in the incidence and symptoms of neuropsychiatric and neurodegenerative disorders.

\section{Methods}

\section{Human samples}

Human NPC were obtained using surgical hippocampal specimens of patients with mesial temporal lobe epilepsy undergoing partial removal of the hippocampus for an attempted surgical cure (Table 1).

\section{Experimental animals and treatments In vivo electroporation}

mGro1 plasmid was mixed with episomal pCagghypbase and a transposable ubiquitin $\mathrm{C}$ promoterdriven EGFP reporter plasmid at a 1:0.7:1 ratio. This mix was delivered by injection through pulled glass capillary pipette to $\mathrm{P} 0-\mathrm{P} 2 \mathrm{C} 57 \mathrm{Bl} / 6$ mice. Pups were then electroporated with electrodes positioned to target the right dorsal hippocampus. Employing Signagel, platinum Tweezertrodes were used for electroporation with 3-5 pulses of $115-135 \mathrm{~V}(50 \mathrm{~ms}$; separated by $950 \mathrm{~ms}$ ) generated with the ECM 830 BTX Electroporator (Harvard Apparatus) [45]. Control mice were electroporated with plasmid lacking Gro1. Animals were killed on day 10 after the procedure, the brains were immediately dissected in phosphate-buffered saline (PBS), and electroporated left halves of the brain were fixed in $4 \%$ PFA for at least $6 \mathrm{~h}$ at $4{ }^{\circ} \mathrm{C}$. On the following day, the brains were embedded in $4 \%$ LMP agarose and sectioned at 70 or $250 \mu \mathrm{m}$ thickness on a Leica VT1200S vibratome, and EGFP expression was analyzed with confocal Leica Sp5-X microscope. The whole hippocampi were isolated from the electroporated halves of the brain for further analysis.

\section{LPS administration}

Two-month-old C57Bl/6 male and female mice (Jackson Laboratory) were injected with LPS $(1 \mathrm{mg} / \mathrm{kg}$, in $200 \mu \mathrm{L}$ of normal saline [NS], i.p.; Sigma-Aldridge) once a day for 5 days. Control mice received NS. Mice were killed $3 \mathrm{~h}$ after the last injection.

\section{E2 pellets and LPS administration}

Two-month-old C57Bl/6 male mice were surgically implanted under isoflurane anesthesia with E2 $(2.5 \mathrm{mg} /$ pellet, $41.666 \mu \mathrm{g} /$ day release; Innovative Research of America, Sarasota, FL) or placebo pellets for 7 weeks. Five days before the mice were sacrificed, LPS or NS was injected as described above. Mice were killed $3 \mathrm{~h}$ after the last injection. There were thus four experimental groups: Placebo/ NS, Placebo/LPS, E2/ NS, and E2/LPS.

\section{Adult NPC cultures and treatments}

Human NPC was isolated from three individual surgical specimens (Table 1). All patients had electrodes (1.5 $\mathrm{mm}$ diameter) implanted in the region of the seizure focus prior to surgical resection, which were removed on average 10 weeks before surgery. The hippocampus was resected, and a piece of hippocampal tissue approximately $2 \mathrm{~cm} \times 1 \mathrm{~cm}$ was placed into $30 \mathrm{~mL}$ of DMEM media (Corning-Cellgro cat\#10-017CV) with antibiotic-antimycotic (Gemini Bio-Products cat\#400-101). Tissue was processed within an hour after dissection. Tissue was dissociated using Papain Dissociation System (Worthington Biochemicals). Cells were isolated according to published protocols [14, 46-48]. Human NPC were then cultured using NeuroCult NS-A Basal Medium (human, cat\# 05750; StemCell Technologies) supplemented with NeuroCult NS-A Proliferation Supplement (human, cat \#05753; StemCell Technologies) as well as $2 \mathrm{mM}$ L-glutamine, $100 \mathrm{U} / \mathrm{mL}$ penicillin, $100 \mu \mathrm{g} /$ $\mathrm{mL}$ streptomycin, $10 \mathrm{ng} / \mathrm{mL} \mathrm{h}$ bFGF, and $20 \mathrm{ng} / \mathrm{mL}$ hEGF.

Murine NPC cultures were prepared according to published protocols $[2,15,49,50]$. Murine NPC were isolated from ten pooled hippocampi of 2-month-old C57Bl/6 mice. NPC were cultured in NeuroCult NSC Basal Medium (mouse, cat $\# 05700$ ) with Proliferation Supplement (mouse, cat \# $057012 \mathrm{mM}$ ), L-glutamine, $100 \mathrm{U} / \mathrm{mL}$ penicillin, $100 \mu \mathrm{g} / \mathrm{mL}$ streptomycin, $10 \mathrm{ng} /$ $\mathrm{mL} \mathrm{m}$ bFGF, and $20 \mathrm{ng} / \mathrm{mL}$ mEGF in Costar 6-Well

Table 1 Patient characteristics

\begin{tabular}{|c|c|c|c|c|c|c|c|}
\hline Patient \# & Gender & $\begin{array}{l}\text { Age, } \\
\text { years }\end{array}$ & Surgical site & $\begin{array}{l}\text { Seizure location } \\
\text { method }\end{array}$ & $\begin{array}{l}\text { Time from electrode } \\
\text { insertion (weeks) }\end{array}$ & $\begin{array}{l}\text { Age of seizure } \\
\text { onset, years }\end{array}$ & Pathology \\
\hline$\# 1$ & Male & 45 & Right hippocampus & Depth electrodes & 12 & 13 & Hippocampal gliosis \\
\hline$\# 2$ & Male & 44 & Left hippocampus & Depth electrodes & 10 & 22 & Normal hippocampus \\
\hline \#3 & Female & 44 & Right hippocampus & Depth electrodes & 10 & 7 & $\begin{array}{l}\text { Hippocampal sclerosis } \\
\text { and gliosis }\end{array}$ \\
\hline
\end{tabular}


Plate with Ultra-Low Attachment Surface (Corning, cat\# 3471).

For both human and murine cultures, after 2 weeks in proliferation conditions, neurospheres were collected, cells dispersed by pipetting, and plated in plates pretreated with ECL cell Attachment Matrix (Upstate, $\left.5-10 \mu \mathrm{g} / \mathrm{cm}^{2}\right)$ at a density of $2.5-5 \times 10^{5}$ per well in 6-well plates or $2-5 \times 10^{4}$ per well in 24-well plates (Basal NeuroCult NSC media with Differentiation Supplement, StemCell Technologies, human cat\# 05754, and mouse cat\# 05703). Cells were placed in differentiating media and allowed to attach for 4-6 $\mathrm{h}$ and then treated. Both human and murine NPC were differentiated in the presence of $10 \mathrm{ng} / \mathrm{mL} \mathrm{IL-1 \beta}$ (Millipore, hIL-1 $\beta$ cat\# IL038, mIL-1 $\beta$ cat\# IL014) or $50 \mathrm{ng} / \mathrm{mL}$ IL-6 (Millipore, hIL-6 cat\#IL006, mIL-6 cat\# IL017) for 10 days. In some experiments, murine NPC was treated with mGro1 protein (Origen, cat\# TP 723259) for $72 \mathrm{~h}$. We used the dose of $80 \mathrm{ng} / \mathrm{mL}$ appeared to be the most effective in HT-22 cells (Fig. 7).

\section{Constructs and transfections}

Lentiviral particles expressing human Gro1 (EF1-luc2Gro1-Ubic) and control lentiviral particles were generated at the Cedars-Sinai Virus Core facility. Lentiviral particles expressing shmGro1 or shScr RNAi were purchased (Santa Cruz Biotechnologies).

For lentiviral transduction, cells growing in proliferating conditions were collected, plated into 6-well plates at a density of $5 \times 10^{5}$ per well, placed in differentiating media, and allowed to attach to plastic for 4-6 $\mathrm{h}$ before 20 multiplicity of infection (MOI) of virus was added with $3 \mu \mathrm{g} / \mathrm{mL}$ polybrene (Santa Cruz Biotechnologies, cat\# sc-134220). After 24 h, cells were washed and fresh media was added. Cells were collected $72 \mathrm{~h}$ after transduction.

\section{Cells}

HT-22 (Millipore, cat\# SCC129) is an immortalized mouse hippocampal cell line subcloned from the HT-4 cell line [51]. The parental HT-4 cell line was derived from the immortalization of mouse neuronal tissues with a temperature sensitive SV40 T-antigen [52]. HT-22 cells were cultured and propagated in DMEM with $10 \% \mathrm{FBS}$, $2 \mathrm{mM}$ L-glutamine, $100 \mathrm{U} / \mathrm{mL}$ penicillin, $100 \mu \mathrm{g} / \mathrm{mL}$ streptomycin, and $20 \mathrm{ng} / \mathrm{mL}$ mEGF. Cells were treated with murine Gro1 and harvested after $72 \mathrm{~h}$.

\section{Quantitative real-time polymerase chain reaction}

Total RNA was isolated from the hippocampi with RNeasy Lipid Tissue Mini Kit (Qiagen, cat\# 74804). cDNA was synthesized from 0.5 to $1 \mu \mathrm{g}$ of purified RNA by iScript Reverse Transcription Supermix (Bio-Rad, cat\# 1708841) according to the manufacturer's instructions.
Quantitative PCR was performed in $20 \mu \mathrm{L}$ reaction using IQ SYBR Green Master Mix and CFX96 Real-Time System standard protocol (Bio-Rad Laboratories, Hercules, CA). Specific validated primers for murine DCX, Ng2, Gro1, and glyceraldehyde-3-phosphate dehydrogenase (GAPDH), as well as human Gro1, fibroblast growth factor 2 (FGF2), and glial cell-derived neurotrophic factor (GDNF), were purchased (SuperArray, Qiagen, Germantown, $\mathrm{MD})$. Triplicate PCR reactions yielded threshold cycle $(\mathrm{Ct})$ average, with a coefficient of variance of $<0.05 \%$, which were used to determine $\Delta \mathrm{Ct}$ values $[\Delta \mathrm{Ct}=\mathrm{Ct}$ of the target gene minus $\mathrm{Ct}$ of the housekeeping GAPDH gene]. A comparative threshold cycle $\left(C_{\mathrm{T}}\right)$ method was used for relative gene expression quantification. All experiments included template-free (water) and reverse transcriptase-minus controls to ensure no contamination. Relative quantities of mRNA in experimental samples were determined, normalized to GAPDH, and expressed in arbitrary units as fold difference from control (control was taken as 1).

\section{Protein isolation and Western blot analysis}

NPC growing in culture were collected in Trizol reagent (Thermo Fisher Scientific, Waltham, MA) and proteins isolated according to the protocol (Molecular Research Center) using radioimmunoprecipitation assay (RIPA) buffer (Cell Signaling, cat\#9806) with Protease Inhibitor Cocktail (Sigma, cat\# P8340). Western blot analysis was performed as described [22]. Thirty to fifty micrograms of protein lysate was resolved by SDS-PAGE and electroblotted onto polyvinylidene difluoride (PVDF) membrane (EMD Millipore, Billerica, MA). The membrane was blocked by $5 \%$ non-fat dry milk in Tris-buffered saline (TBST; $50 \mathrm{mM}$ Tris- $\mathrm{HCl}, \mathrm{pH}$ 7.6, $150 \mathrm{mM} \mathrm{NaCl}, 0.05 \%$ Tween 20) and incubated overnight with primary antibodies at $4{ }^{\circ} \mathrm{C}$, followed by incubation with corresponding secondary antibodies (Sigma-Aldrich, St. Louis, MO) for $2 \mathrm{~h}$ at room temperature. Immunoreactive bands were detected using Bio-Rad Molecular Imager ${ }^{\circ}$ ChemiDoc $^{\text {Tw }}$ XRS and Image Lab ${ }^{\text {Tw }}$ Software (BioRad Laboratories). The following antibodies were used: Gro1 (Novus cat\# NBP1-51188), SA- $\beta$-gal (LSBio cat\# LS-B10989), DCX (Santa Cruz Biotechnologies, cat\# sc-271390), Tuj-1 (Abcam,cat\# ab182-07), Ng2 (Millipore, cat\# AB5320), total p65 (Santa Cruz Biotechnologies, cat\# sc-8008), phospho-p65 (Ser536; Cell Signaling, cat\# 3033), murine Gro1 (R\&D, cat\# AF-453), GFAP (Millipore, cat\# mAB3402), cleaved caspase 3 (Cell Signaling, cat\# 9664), Ki67 (Abcam, cat\# ab15580), p16 (Santa Cruz Biotechnologies, cat\# sc-1661), ionized calcium-binding adapter molecule 1 (Iba1; Abcam, cat\# ab107159), PDGF $\alpha$ R (LSBio, cat\# LS-B6056), and GAPDH (Cell Signaling, cat \#5174). 
Immunohistochemistry and immunocytochemistry

To detect Gro1 in SGZ of the hippocampus, the right half of the brain from three randomly selected mice was fixed and sections from 0.36 to $0.6 \mathrm{~mm}$ lateral to the midline [53] were cut. Five randomly selected slides from each mouse were analyzed. Paraffin-embedded brain sagittal sections $(5 \mu \mathrm{m})$ were double-labeled with primary antibodies conjugated with Alexa 488 or Alexa 568 fluorescent dyes (1:400, Thermo Fisher). The following primary antibodies were used: mouse Gro1 (RnD, cat\# AF-453), Sox2 (Millipore, cat\#AB56030), DCX (Abcam, cat\# ab18723), and GFAP (Millipore, cat\# MAB3402 or Abcam, cat\# ab7260). Nuclear DNA was stained with DAPI (Sigma, cat\#D9542), and the stained sections were covered with ProLong Gold (Thermo Fisher, cat\#P36935). Antigen retrieval was performed on paraffin-embedded tissues in Target Retrieval Solution (Dako, cat\# S1699).

Neurospheres growing in proliferation media for 2 weeks were collected, dissociated by pipetting with a micropipette, and plated on coverslips pretreated with ECL matrix in 24-well plates in differentiation media. Cells were allowed to attach to coverslips for 4-6 h and then treated. Areas with the highest cell density were imaged with Leica $\times 20$ Plan-Apo lens on a Leica Sp5-X confocal microscope. The number of double positive and total cells was counted in 5-15 fields in two independent experiments (total number of cells analyzed was between 500 and 3000 depending on the experiment). The following primary antibodies were used: Tuj-1 (Stem Cell Technology, cat\# 01409 or Abcam, cat\# ab182-07), Ng2 (Millipore, cat\# AB5320), GFAP (Millipore, cat\# MAB3402 or Abcam, cat\# ab7260), Ki67 (Abcam, cat\#ab15580), DCX (Abcam cat\#ab18723), and p16 (Santa Cruz cat\# sc-1207 or sc-1661).

\section{SA- $\beta$-galactosidase activity}

SA- $\beta$-galactosidase enzymatic activity was assayed in vitro using a $\beta$-gal staining kit (Senescence Cell
Staining Kit, Sigma-Aldrich) according to the manual. Briefly, 10,000 cells were plated in 12-well plates, treated for the indicated times, washed with PBS $(\mathrm{pH}$ 6.0), fixed, and stained with 5-bromo-4-chloro-3-indolyl-h-D-galactopyranoside (X-Gal) overnight at $37{ }^{\circ} \mathrm{C}$. Only senescent cells stain at $\mathrm{pH}$ 6.0. SA- $\beta$-gal positivity was assessed in 6-well plates in triplicate, with 1000 cells per field counted in three fields per well.

\section{Statistical analysis}

Differences in protein and mRNA levels were assessed by one or two-way ANOVA followed by Tukey's test to correct for post-hoc multiple testing. The number of cells positive for Ki67, Ng2, Tuj-1, p16, or GFAP across the groups was assessed with a two-tailed $t$ test. For all testing, data were $\log$ transformed prior to analysis where data were not normally distributed. Results were inspected to confirm fit. Differences were considered statistically significant at the two-tailed $p$ value of $<0.05$.

\section{Results}

Proinflammatory cytokines induce Gro1 in human and murine hippocampal NPC

Human NPC were isolated individually from the hippocampal tissue derived from surgical samples of three patients with mesial temporal lobe epilepsy (Table 1). NPC formed spheres, which were cultured under proliferative conditions for 2 weeks. Cells were initially shown to express SOX2/ nestin, markers of early neuronal progenitors. Cells were dispersed and plated under differentiating conditions for 1 week when they began to lose SOX2 and to acquire DCX, a marker of neuroblasts (Fig. 1). This confirmed progenitor properties of the NPC.

We first examined how the exposure of NPC to IL-1 $\beta$ affects the expression of growth factors. Differentiating cells were treated with IL- $1 \beta$ for 10 days. Real-time PCR revealed marked induction ( $26 \pm 3$-fold) of Gro1 mRNA levels in IL-1 $\beta$-treated NPC compared to untreated
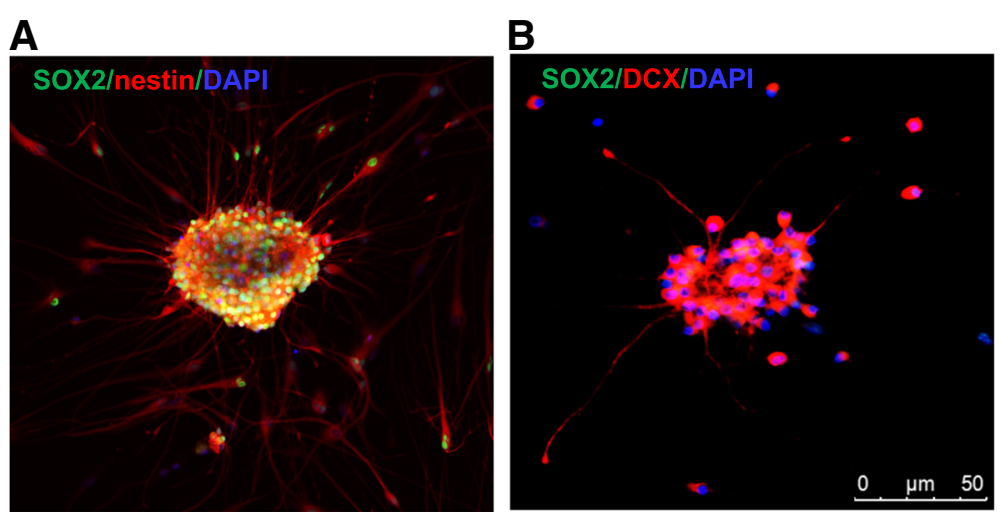

Fig. 1 Confocal image of human NPC in culture. a Proliferative conditions. Cells express both SOX2 and nestin, markers of stem/early progenitor cells. b Differentiating conditions. After 1 week, NPC begin to lose stem cell marker Sox2 and to acquire neuroblast marker DCX 
controls $(t(4)=53.9, p<0.0001)$, while growth factors for neuronal progenitors, including GDNF and FGF2, were not significantly induced (Fig. 2a).

Exposure of differentiating human NPC to IL-1 $\beta$ or IL-6 for 10 days also resulted in marked induction of Gro1 protein levels $(F 2,4=106.94, p=0.0003$ vs untreated cells, Fig. 2b,c). It is possible that Gro1 can be activated by cytokine-induced $\mathrm{NF \kappa B}$, which has been shown to increase Gro1 transcription [37, 54]. Phosphorylation of p65 (RELA) subunits is required for transcriptional NFKB activation [36]; in human NPC, we found upregulated expression of both total $(F 2,4=330.26, \quad p<0.0001)$ and phospho-p65 $(F 2,4=108.81, p=0.0001)$ subunits after treatment with IL-6 and with IL-1 $\beta$ (Fig. 2b, c).

We repeated these experiments with murine NPC isolated from the hippocampus of 2-month-old mice and found significant upregulation of phospho-p65 $(F 2,7=74.73, p<0.001)$ followed by induction of Gro1 after 10 days of exposure to IL- $1 \beta$ or IL- $6(F 2,7=34.3$, $p=0.0002)$ (Fig. 2d, e).

\section{Gro1 suppresses new neuron development in human and murine NPC}

We next examined how upregulated Gro1 affects neurogenesis. Human NPC were infected with hGro1expressing lentivirus and cultured for $72 \mathrm{~h}$ under differentiating conditions.

Gro1 overexpression significantly affected the neuronal markers $(F 1,2=65.39, p=0.0149)$, resulting in decreased levels of neuroblast marker DCX $(F 1,2=78.47, p=0.0125)$, while $\mathrm{Ng} 2$, a marker of oligodendrocyte progenitors, was upregulated $(F 1,2=476.61, p=0.0023)$ (Fig. 3a, b).

\section{Gro1 induces senescence in neuroblasts}

We further assessed the mechanisms underlying Gro1induced loss of neuroblasts. As Gro1 is a secreted

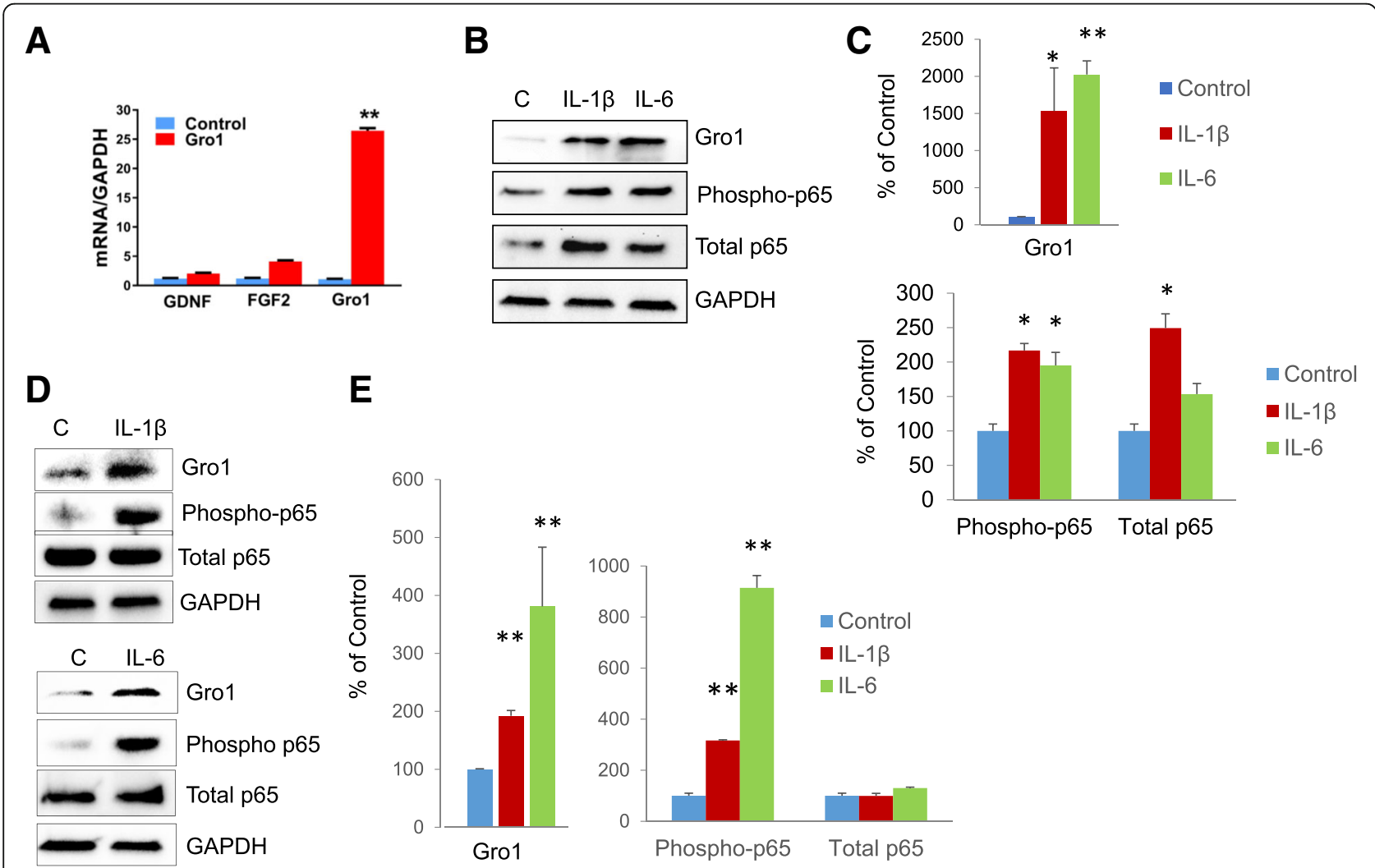

Fig. 2 Proinflammatory cytokines induce Grol expression in human and murine hippocampal NPC. a mRNA levels of growth factors in hNPC treated with IL-1 $(10 \mathrm{ng} / \mathrm{mL})$ for 10 days. Data are shown as mean \pm SEM of three independent experiments. All samples from three experiments were run together in triplicate and normalized against GAPDH. Results are expressed in fold change vs untreated control taken as 1 ; **p $<0.01$. b Western blot analysis of Gro1 and NFKB subunits in hNPC treated with IL $1 \beta(10 \mathrm{ng} / \mathrm{mL})$ or IL $6(50 \mathrm{ng} / \mathrm{mL})$ for 10 days. C, untreated control. Three independent experiments were performed, and representative blots are shown. $\mathbf{c}$ Intensities of protein bands were quantified from three individual experiments, normalized to GAPDH, and presented as percent of control (untreated cells); ${ }^{*} p<0.05$, ${ }^{* *} p<0.01$ vs control in post-hoc pair-wise $t$ test. $\mathbf{d}$ Western blot analysis of Gro 1 in $\mathrm{mNPC}$ treated with IL-1 $\beta(10 \mathrm{ng} / \mathrm{mL})$ or $\mathrm{LL}-6(50 \mathrm{ng} / \mathrm{mL})$ for 5 days. C, untreated control. Three independent experiments were performed, and representative blots are shown. e Intensities of protein bands were quantified from three individual experiments, normalized to GAPDH, and presented as percent of control (untreated cells); ${ }^{*} p<0.05$, ${ }^{* *} p<0.01$ vs control in post-hoc pair-wise $t$ test 

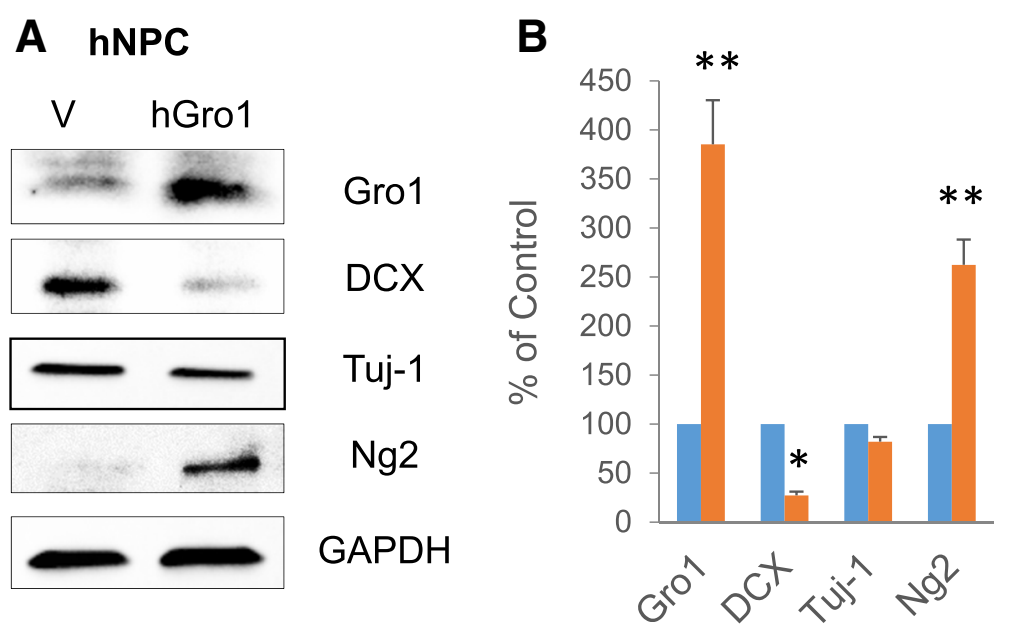

Fig. 3 Gro1 suppresses new neuron development in human NPC. a Western blot analysis of neurogenesis markers. Human NPC (hNPC) were infected with lentivirus expressing human Gro1 (hGro1) or empty vector ( ). Three independent experiments were performed, and representative blots are shown. $\mathbf{b}$ Intensities of protein bands were quantified from three individual experiments, normalized to GAPDH, and presented as percent of control (empty vector); ${ }^{*} p<0.05,{ }^{* *} p<0.01$. vs control in post-hoc pair-wise $t$ test

protein, and neuronal progenitors express Gro1 receptor CXCR2 [40], we isolated NPC from murine hippocampus and treated them with mGrol protein $(80 \mathrm{ng} / \mathrm{mL})$ for $72 \mathrm{~h}$. Control cells were untreated. This dose was identified as the most effective in HT-22 cells, as described below. mGro1 treatment resulted in strong induction of SA- $\beta$-gal $(F 1,2=41.93, \quad p=0.0230)$, an ultimate marker of senescence $[55,56]$, as well as induced expression of the cyclin-dependent kinase inhibitor p16 $(F 1,2=33,776, p<0.0001)$, indicating activation of the senescence pathway and proliferation arrest. Indeed, Ki67, a marker of proliferation, was downregulated in Gro1-treated cells $(F 1,2=48.42, p=0.0200)$, as was the neuroblast marker DCX $(F 1,2=26.46, p=0.0358)$ (Fig. 4a, b). Tuj-1, a marker of newly developing neurons, was also suppressed $(F 1,2=281.69, p=0.035)$, while the oligodendrocyte progenitor marker Ng2 was induced $(F 1,2=55.30, p=0.0176)$. As apoptosis is suppressed in senescent cells, we observed decreased expression of cleaved caspase 3 in NPC treated with Gro1 $(F 1,2=225.59, p=0.0044)$ (Fig. $4 \mathrm{a}, \mathrm{b})$. To examine the effects of Gro1 on DCX transcription, we assessed DCX mRNA by real-time PCR and observed 40\% downregulation, confirming a decrease in neurogenesis after Gro1 treatment $(F 1,2=206.76, p=0.048$, Fig. $4 c)$.

To confirm cells undergoing senescence were neuroblasts, we performed immunocytochemistry studies to assess the number of proliferating cells expressing neuroblast and glial markers. Treatment of differentiating NPC with Gro1 for $72 \mathrm{~h}$ markedly decreased the percentage of Tuj-1+ neuroblasts positive for Ki67 $(t(15)=-3.9, \quad p=0.0061)$, while the number of $\mathrm{Ng} 2$ +/Ki67+ oligodendrocyte progenitor cells was increased $(t(18)=4.64, p=0.0002)$. By contrast, no changes were observed in GFAP+/Ki67+ cells between treated and untreated groups, indicating that the proliferation rate of astrocytes did not change (Figs. $5 \mathrm{a}$ and 6). Moreover, we found increased numbers of Tuj-1-positive neuroblasts expressing p16 $(t(14)=2.74, p=0.0160)$ and decreased numbers of $\mathrm{Ng} 2+/ \mathrm{p} 16+$ cells $(t(18)=-3.8, p=0.049)$ (Figs. $5 \mathrm{~b}$ and 6 ). These results show that the effects of Gro1 in NPC are cell type-specific, inducing proliferation arrest and likely senescence in neuroblasts while increasing oligodendrocyte progenitor proliferation.

\section{Gro1 induces senescence and arrest proliferation in murine hippocampal neurons}

To further confirm that Gro1 acts to arrest neuronal cell proliferation, we tested the effects of Gro1 in the immortalized hippocampal neuronal cell line HT-22. These cells exhibit properties of newly developing neurons, as they lack the cholinergic and glutamate receptors seen in mature neurons [51, 52], yet still express DCX and Tuj-1, which are markers of immature neurons. Cells were treated with increasing doses of Gro1 or left untreated and analyzed after $72 \mathrm{~h}$. Gro1 dose-dependently induced SA- $\beta$ gal $(F 3,6$ $=16.54, p=0.0026)$ as well as p16 $(F 3,6=20.76, p=0.0014)$ expression, while Ki67 expression was inversely downregulated $(F 3,6=29.38, p=0.0006)$ and expression of cleaved caspase 3 was reduced $(F 3.6=15.59, p=0.031)$; treatment with the $80 \mathrm{ng} / \mathrm{mL}$ dose of Gro1 also resulted in decreased expression of $\operatorname{DCX}(F 3,9=15.81, p=0.0006)$ and Tuj-1 $(F 3,6=16.25, p=0.0028) \quad$ (Fig. 7a, b). The number of SA- $\beta$-gal-positive senescent cells in response to Gro1 treatment was markedly increased $(F 2,15=21.16, p<0.0001)$ (Fig. 7c, d), indicating that Gro1 induces senescence, 


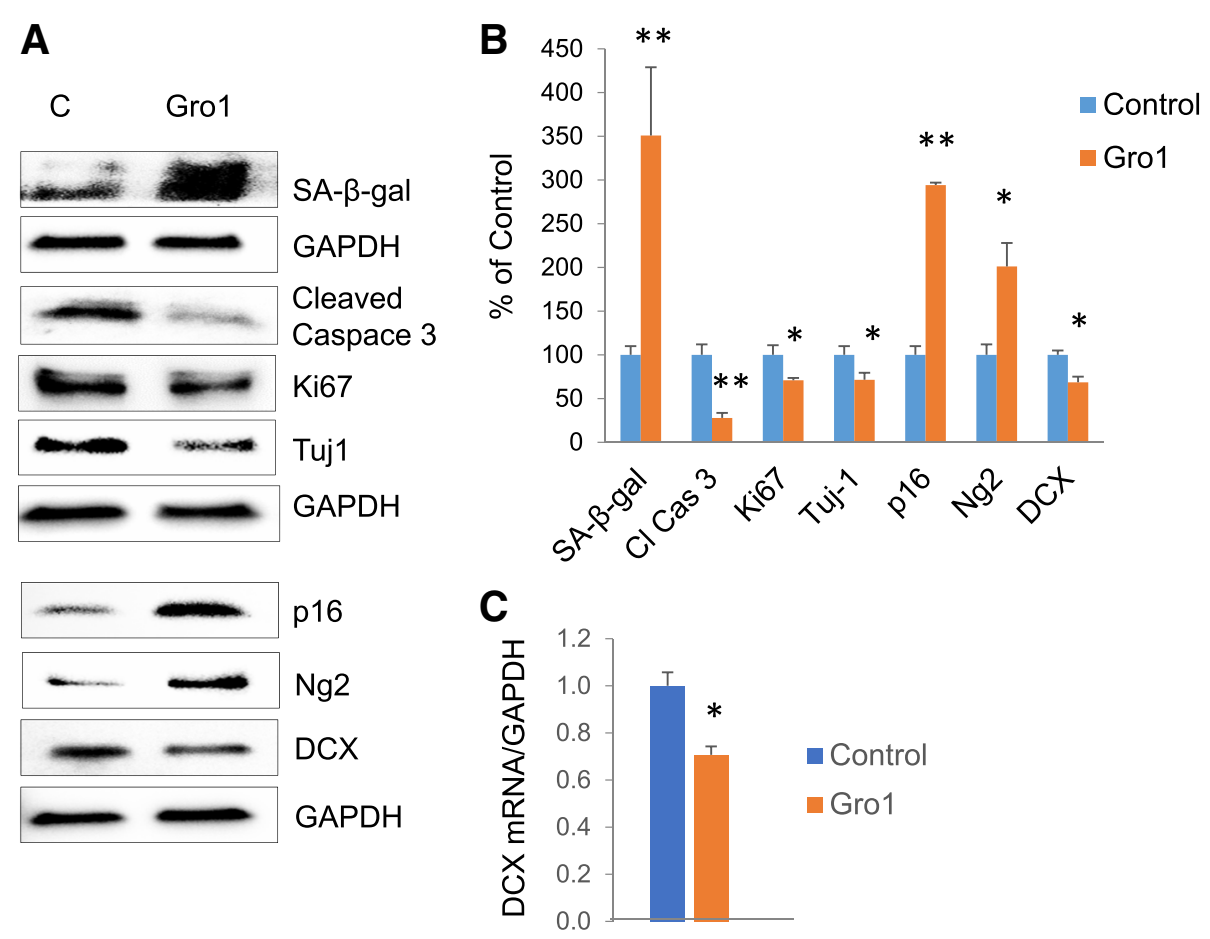

Fig. 4 Grol induces senescence in neuroblasts. a Western blot analysis of markers of neurogenesis, senescence, apoptosis, and proliferation in murine NPC treated with $\mathrm{mGro} 1$ protein $(80 \mathrm{ng} / \mathrm{mL})$. Three independent experiments were performed, and representative blots are shown. C, untreated control. $\mathbf{b}$ Intensities of protein bands were quantified from three individual experiments, normalized to GAPDH, and presented as percent of control (untreated cells). c DCX mRNA levels in mNPC treated with Grol. Data are shown as mean \pm SEM of three independent experiments. All samples from three experiments were run together in triplicate and normalized against GAPDH. Results are expressed in fold change vs control (untreated cells) taken as $1 .{ }^{*} p<0.05,{ }^{*} p<0.01$ vs control in post-hoc pair-wise $t$ test
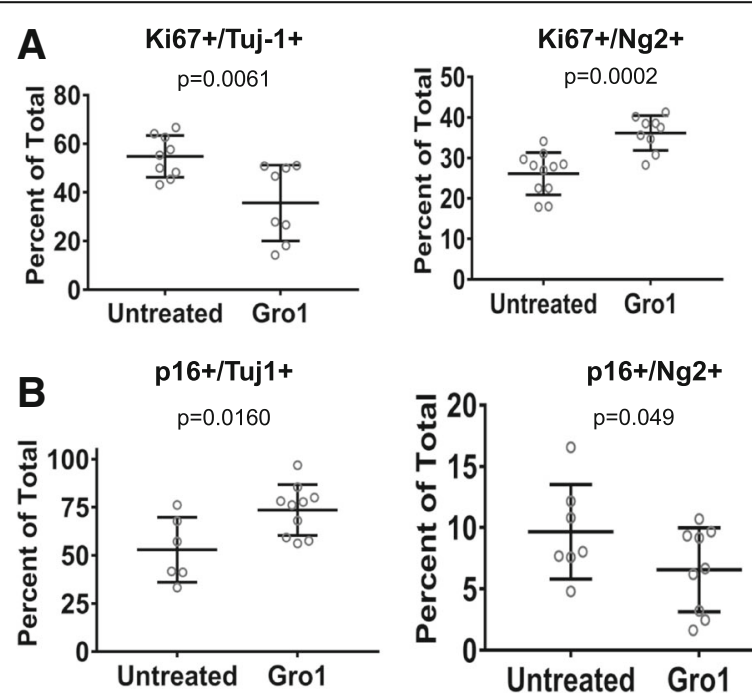

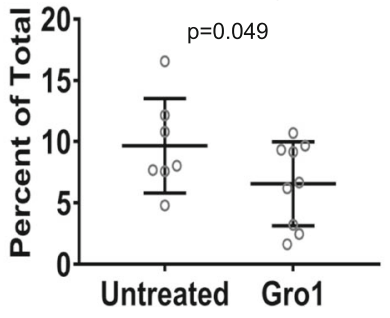

Fig. 5 Grol suppresses proliferation of neuroblasts and increases proliferation of oligodendrocytes. Immunocytochemistry of mNPC treated with Gro1 $(80 \mathrm{ng} / \mathrm{mL}$ ) for $72 \mathrm{~h}$ or left untreated. a Cells were co-stained for Ki67- and Tuj-1, Ng2, or GFAP. The graphs depict the percentage of Ki67+ proliferating cells among Tuj-1+ neuroblasts, Ng2+ oligodendrocyte precursors, or GFAP+ astrocytes. b Cells were co-stained for p16, Tuj-1, Ng2, and GFAP. The graphs depict the percentage of p16+ non-proliferating cells among Tuj-1+ neuroblasts, Ng2+ oligodendrocyte precursors, or GFAP+ astrocytes. Counting was performed in triplicate (> 500 cells per sample). Data were tested across groups using $t$ test or Wilcoxon ranksum test. Data are presented as a mean \pm SEM 


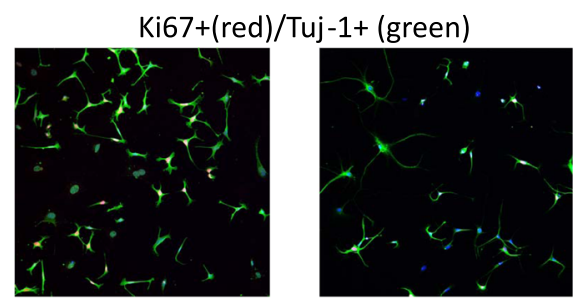

Ki67+(red)/Ng2+ (green)

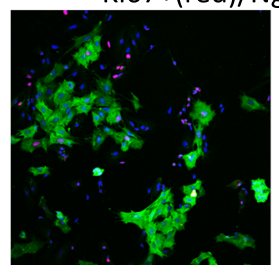

Ki67+(red)/GFAP+ (green)

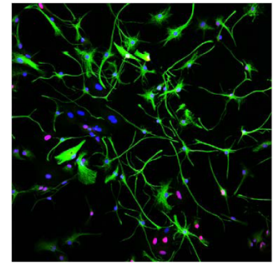

Untreated
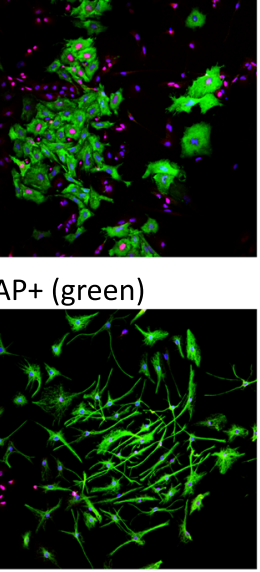

Gro1

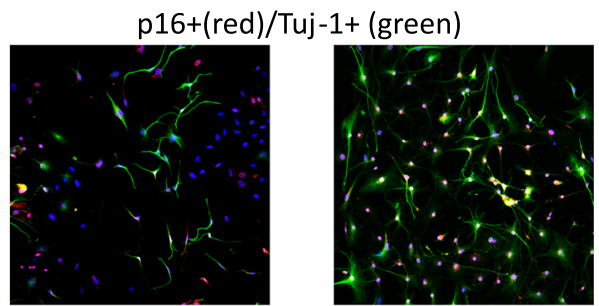

$\mathrm{p} 16+($ green $) / \mathrm{Ng} 2+($ red $)$
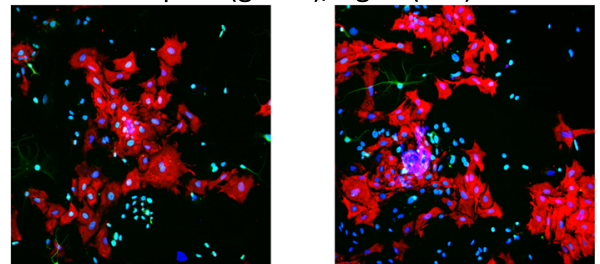

$\mathrm{p} 16+($ green $) / G F A P+($ red $)$

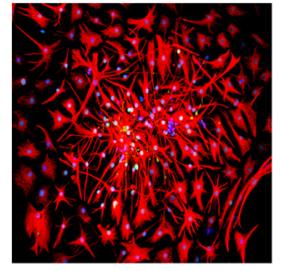

Untreated

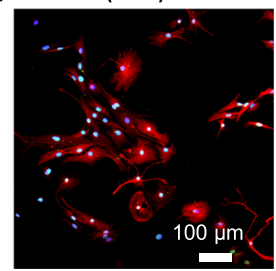

Gro1

Fig. 6 Gro1 suppresses proliferation of neuroblasts and increases proliferation of oligodendrocytes. Confocal image of murine NPC under differentiating conditions treated with Gro1. Cells were double-labeled with either Ki67 or p16, and Tuj-1, Ng2, and GFAP. Representative images are shown

decreases apoptosis, and arrests proliferation of neuronal cells, likely through p16 induction.

\section{Gro1 suppresses neurogenesis in the hippocampus of newborn mice}

As a proof of concept, we electroporated a plasmid expressing $\mathrm{mGro} 1$ into the brain of 1 -day-old $\mathrm{C} 57 \mathrm{Bl} / 6$ mice; control mice were electroporated with a plasmid expressing empty vector. Ten days later, mice were sacrificed and the hippocampi isolated. Grol expression in the hippocampus was confirmed by visualizing EGFP reporter vector on confocal microscopy (Fig. 8a). Hippocampal Gro1 electroporation led to increased Gro1 $(F 1,2=337.05, p=0.030)$ and Iba1 expression, a marker of activated microglia $(F 1,2=22.73, p=0.0413)$. We also observed a marked decrease in DCX expression $(F 1,2=815.04, \quad p=0.0012)$, indicative of decreased neuroblast number and confirming our in vitro finding that Gro1 suppresses neurogenesis. PDGF $\alpha$ R, a marker of early oligodendrocyte precursors, was upregulated $(F 1,2=25.21, \quad p=0.0375)$ in agreement with the pro-proliferative effect of Gro1 on early-stage oligodendrocytes [44]. Of note, SA- $\beta$-gal was undetectable (not shown), but p16 was induced in the hippocampus of mice treated with Gro1 $(F 1,2=50.26, \quad p=0.0193)$ (Fig. 8b, c).
Gro1 suppression results in decreased senescence and the induction of neuronal markers in murine NPC

To examine the effects of Grol suppression on NPC differentiation, we infected murine NPC with lentivirus expressing shGro1 RNAi and analyzed cells $72 \mathrm{~h}$ later. Gro1 downregulation was confirmed by both Western blot $(F 1,3=17.48, p=0.0249)$ and real-time PCR $(F 1,2=815.47, p=0.0012)$ (Fig. 9a-c). Cells with suppressed Gr01 showed upregulated DCX protein $(F 1,4=13.96, p=0.0202)$ and mRNA levels $(F 1,2=$ $52,863, p<0.0001$ ) (Fig. 9a-c). SA- $\beta$ gal was also markedly reduced $(F 1,2=159.75, p=0062)$, likely resulting in new neuron development $(9 a-c)$. At the same time, PDGF $\alpha$ R expression was downregulated $(F 1,2=21.91, p=0.0427)$ (Fig. 9a, b) in agreement with observed pro-proliferative effects of Gro1 on early oligodendrocyte progenitors [35]. Thus, Gro1 suppression results in increased neurogenesis and decreased oligodendrogenesis.

Gro1 is expressed in early neuronal progenitors in the SGZ of the hippocampus

We analyzed the expression of Gro1 at the site of neurogenesis in the SGZ of the dentate gyrus of the adult murine hippocampus. Gro1 was expressed in cells expressing SOX2, an early marker of neuronal progenitors, 

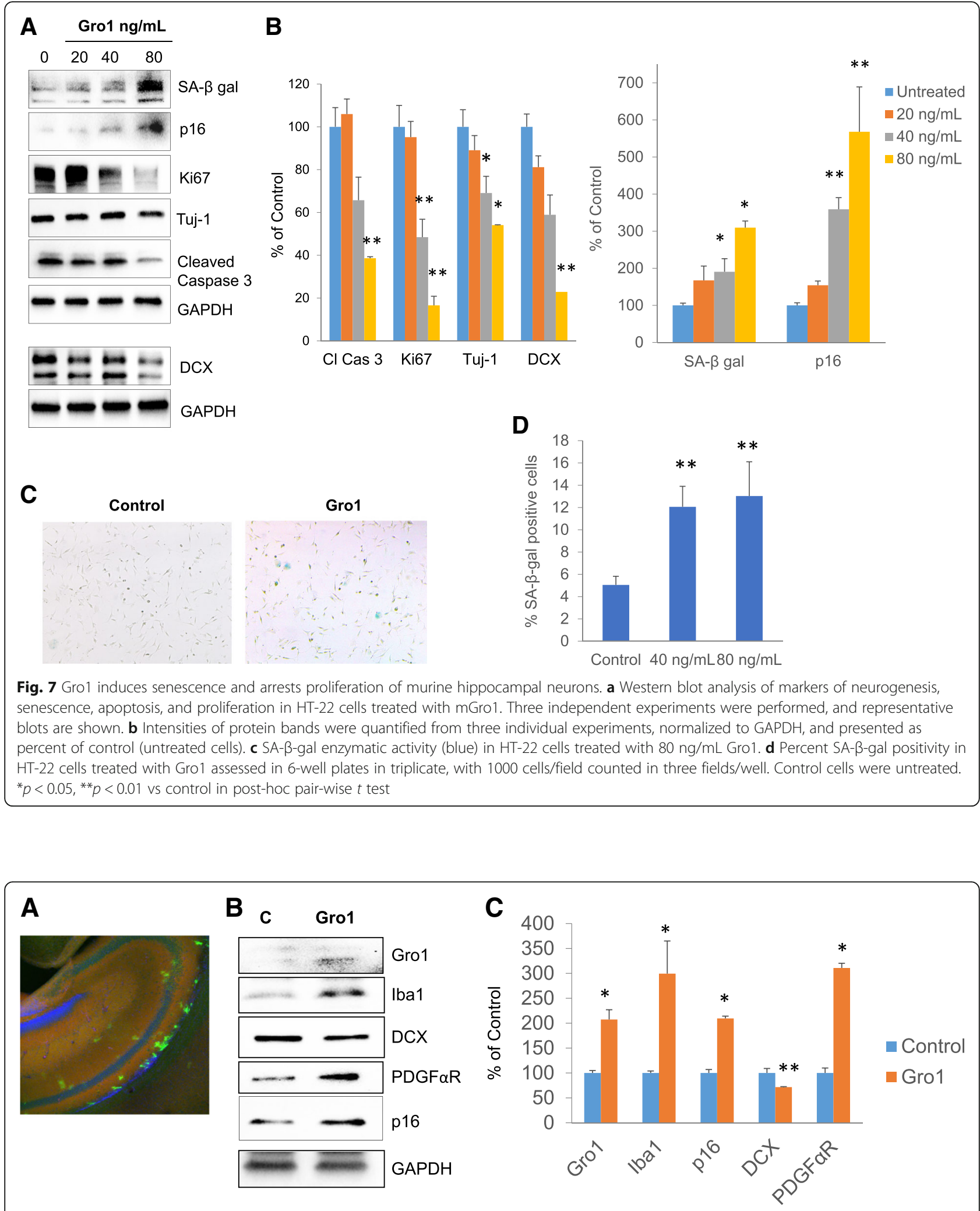

Fig. 8 Gro1 suppresses hippocampal neurogenesis in vivo. a Confocal image of murine hippocampus 10 days after in vivo Gro1 electroporation. Green (EGFP), Gro1-expressing plasmid. b Representative Western blot analysis of hippocampal neurogenesis in mice electroporated with plasmid expressing $\mathrm{mGro} 1$ or control (C, empty vector). $\mathbf{c}$ Intensities of protein bands were quantified from three individual mice/group, normalized to $\mathrm{GAPDH}$, and presented as percent of control (empty vector). ${ }^{*} p<0.05,{ }^{* *} p<0.01 \mathrm{vs}$ control in post-hoc pair-wise $t$ test 


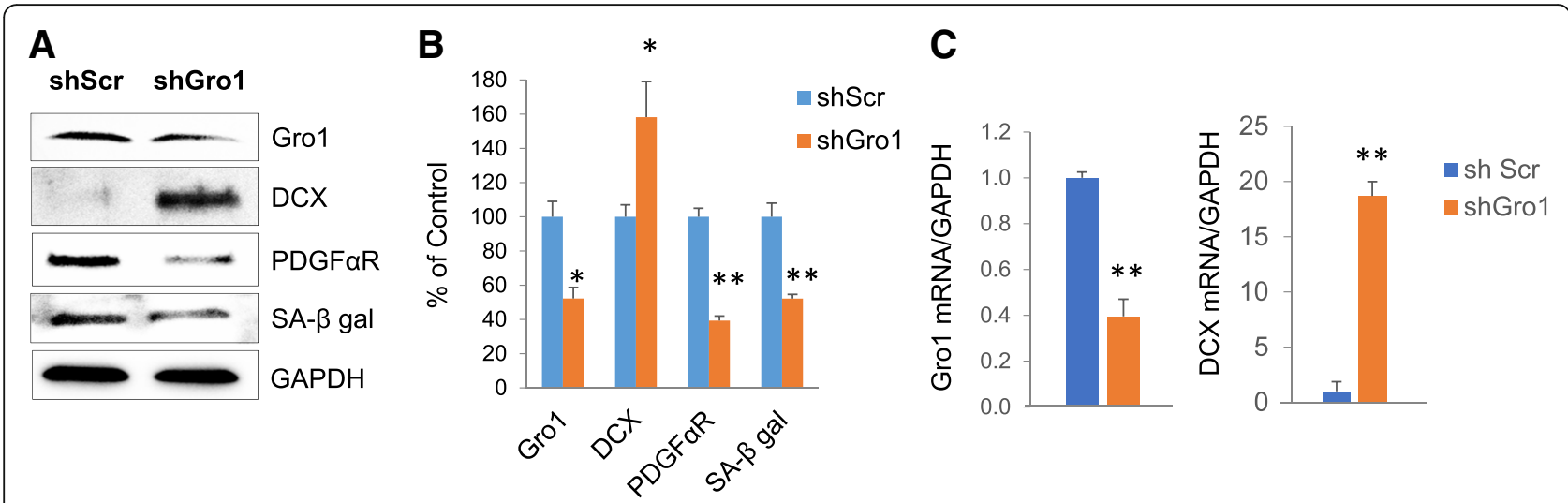

Fig. 9 Gro1 suppression leads to increased expression of neuroblast marker DCX and decreased senescence. a Western blot analysis of mNPC infected with lentivirus expressing shGro1 or sh scramble (shScr) RNAi. b Intensities of protein bands were quantified from three individual experiments, normalized to GAPDH, and presented as percent of control (shScr). c Grol and DCX mRNA levels in mNPC infected with lentivirus expressing shGrol or shScr RNAi. Data are shown as mean \pm SEM of three independent experiments. All samples from three experiments were run in triplicate and normalized against GAPDH. ${ }^{*} p<0.05,{ }^{* *} p<0.01$ vs control in post-hoc pair-wise $t$ test

while no co-localization of Gro1 with DCX+ neuroblasts or GFAP+ astrocytes was observed (Fig. 10). These results suggest that Gro1 is expressed by and likely secreted from early progenitors, affecting SGZ cell differentiation.

\section{Gro1 is markedly induced in the male hippocampus and blunted in females during systemic inflammation}

To test the effects of systemic inflammation on Gro1 expression in the hippocampus, 2-month-old male and female mice were injected with $1 \mathrm{mg} / \mathrm{kg}$ LPS i.p. once daily for 5 days. Control mice received NS. Mice were sacrificed $3 \mathrm{~h}$ after the last injection.

Two-way ANOVA analysis revealed the significant interaction of sex and LPS treatments for expression of Gro1 $(F 1,22=6.31, p=0.0198)$, DCX $(F 1,22=5.02$, $p=0.0355)$, and $\mathrm{Ng} 2(F 1,22=14.10, p=0.0011)$. Compared to NS control, the male hippocampus after LPS treatment showed significantly upregulated Gro1 expression $(t(22)=4.65, p=0.007)$ as well as decreased DCX $(t(22)=-5.54, p<0.001)$ and increased Ng2 protein levels $(t(22)=6.84, p<.0001) \quad($ Fig. 11a-c). These data support our hypothesis that elevated Gro1 is associated with decreased neurogenesis. However, in females, LPS did not induce Gro1 expression, and no significant changes in DCX and Ng2 were observed compared to control females injected with NS (Fig. 11a-c).

Significant effects of sex $(F 1,14=4,6, p=0.0488)$ and LPS treatment $(F 1,15=1020, p<0.0001)$ were also seen in Gro1 mRNA response. Gro1 mRNA levels were increased in the female hippocampus in response to inflammation, albeit at a much lower rate than in male mice $(t(15)=22.4, p<0.001)$ (Fig. 11c).

We also measured IL-1 $\beta$ expression in the hippocampus of males and females after LPS treatment and found significantly higher IL-1 $\beta$ mRNA levels in male than in female hippocampus $(t(15)=20.20, p<0.001)$ (Fig. 11d).
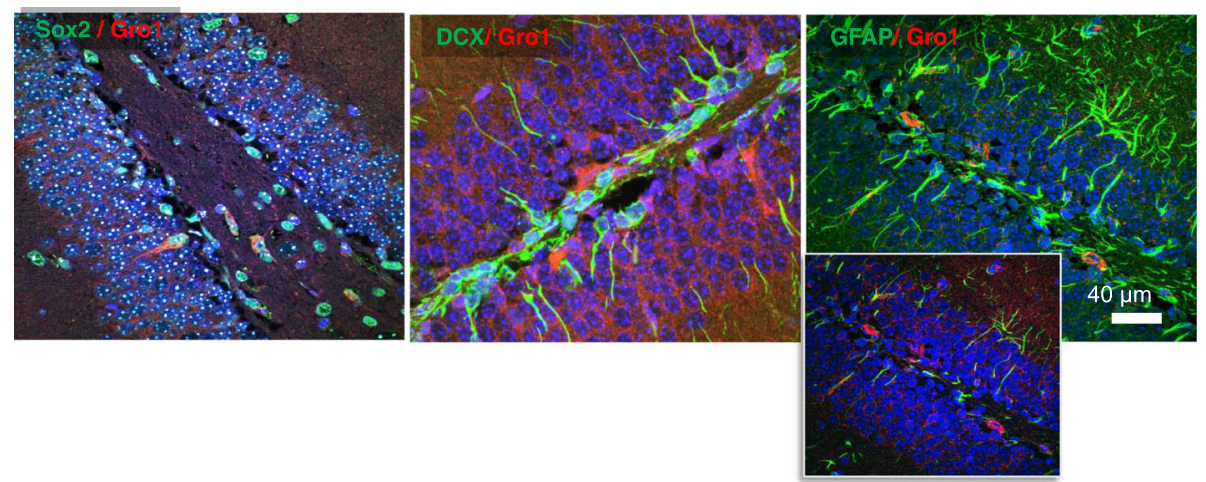

Fig. 10 Gro1 is expressed in Sox2-positive early neuronal progenitors. Representative confocal images of the SGZ in the adult murine hippocampus. Gro1 (red) is co-localized with Sox2 (green; left), but not with DCX (green; center) or GFAP (green; right). Inset with a dimmed green channel for better visualization demonstrates lack of co-localization between GFAP and Gro1 


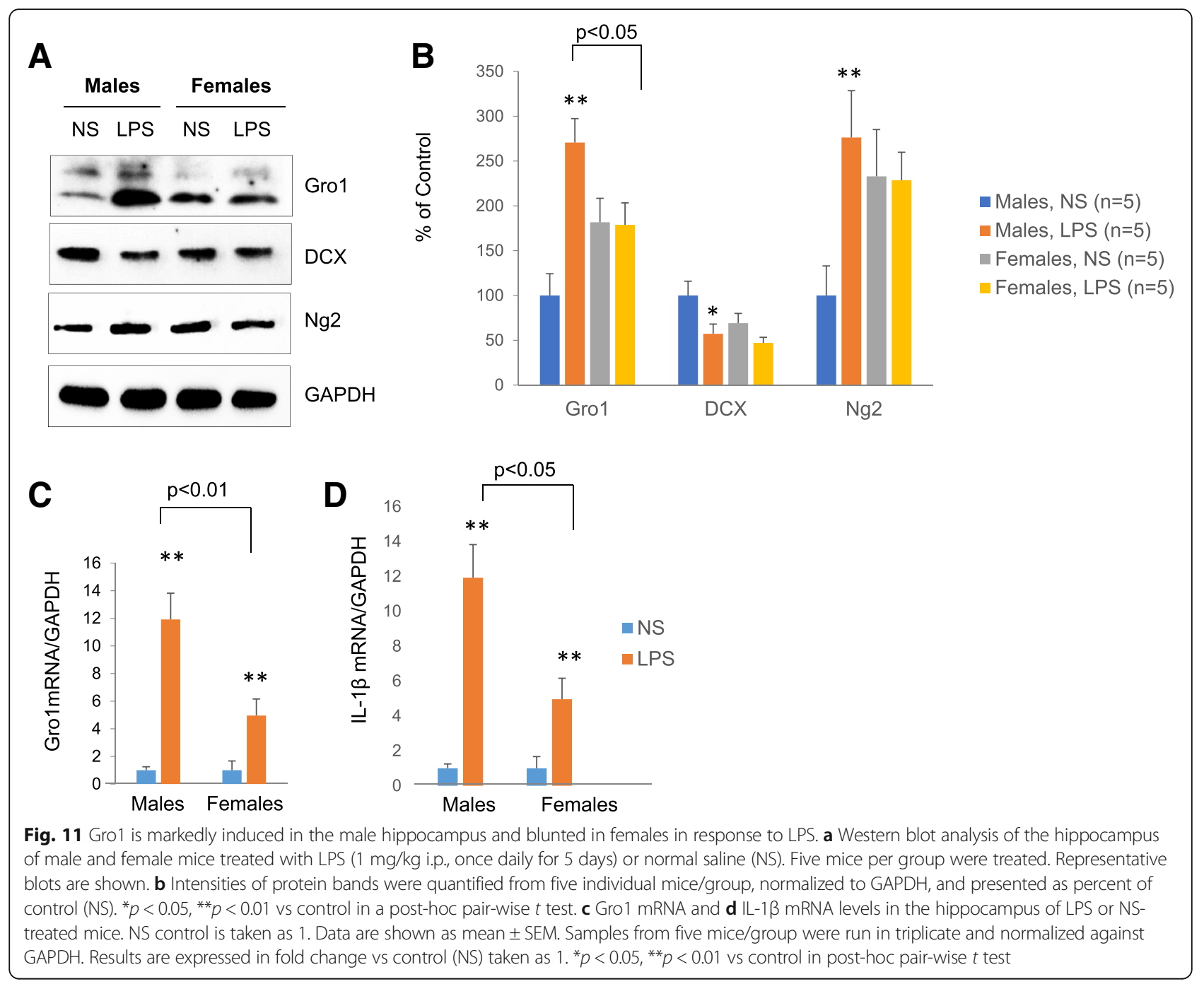

These results suggest a sexual dimorphism in neurogenesis in response to inflammation.

\section{E2 treatment suppresses LPS-induced Gro1}

To test whether differential responses to inflammation are attributed to female sex hormones, 2-month-old male mice were implanted with pellets releasing E2 or placebo for 6 weeks. The concentration of circulating E2 released by the pellet is high for males but is half of the E2 level observed in pregnant females [57]. Mice were challenged with LPS or NS as described above and sacrificed. Mice were divided into four experimental groups: Placebo/ NS, Placebo/ LPS, E2/NS, and E2/LPS. As E2 is a major regulator of pituitary prolactin [58], the efficacy of the E2 treatment was confirmed assessing prolactin protein levels in the pituitary of experimental mice (Fig. 12a). Analysis showed significant crossover interaction between E2 and LPS treatments for Grol $(F 1,16=5.57, p=0.0313)$, DCX $(F 1,22$
$=14.81, p=0009)$, and $\mathrm{Ng} 2(F 1,16=14.68, p=0.0015)$. Compared to placebo-treated mice, E2-treated mice showed blunted hippocampal Gro1 response to LPS. In Placebo/LPS mice, Gro1 protein was induced $\sim 60 \%$ relative to control (Placebo/NS) $(t(16)=4.79, p=0.0010)$, while no induction was observed in E2/LPS mice (Fig. 12b, c).

Similarly, there was a significant interaction between E2 and LPS on LPS-induced Gro1 mRNA levels $(F 1,9=7.08$, $p=0.0260)$. In the LPS group, Gro1 mRNA expression was lower in E2-treated mice compared to placebo-treated mice $(t(9)=-4.56, p<0.0061)$ (Fig. 12d).

Of note, in Placebo/LPS mice, Gro1 induction was accompanied by decreased DCX $(t(16)=4.99, p=0.0001)$ and increased $\mathrm{Ng} 2(t(16)=4.99, p=0.0007)$ protein levels compared to Placebo/NS controls, indicating a decreasing proliferation of neuroblasts and increasing proliferation of oligodendrocyte precursors. However, no differences in DCX or Ng2 were observed between 


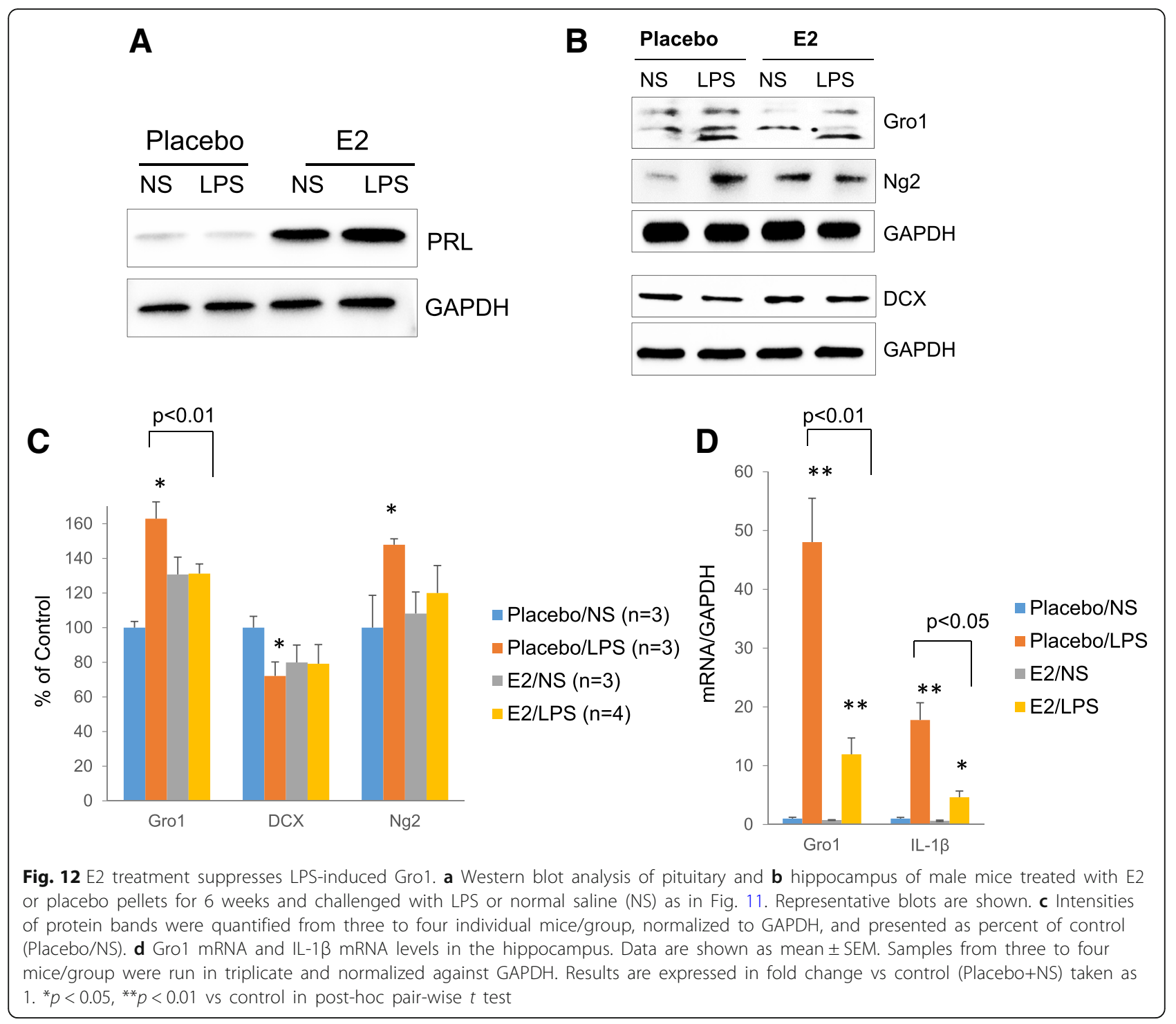

E2/LPS- and E2/NS-treated mice (Fig. 12b, c). Thus, blunted Gro1 response to LPS in the female hippocampus is at least partially due to the suppressive effects of estradiol.

Similar to what was observed in females, levels of IL-1 $\beta$ mRNA were significantly lower in the hippocampus of E2/LPS male mice as compared to control Placebo/LPS mice $(t(9)=-4.0, \quad p=0.023) \quad$ (Fig. 12d), suggesting that E2 may suppress LPS-triggered Gro1 activation by inhibiting IL-1 $\beta$ expression in hippocampus.

\section{Discussion}

We show here that the chemokine Gro1 induced in response to inflammation triggers senescence and arrests development of new neurons in the hippocampus and that the magnitude of this response is sex-dependent.
In mouse brain, Gro1 is expressed in Sox2-positive neuronal progenitors, but not in DCX-positive neurons or astrocytes. In both human and murine NPC, and in the murine hippocampus, inflammatory stimuli induce Gro1 transcription and translation.

Our results indicate that Gro1 triggers premature senescence in newly developing neurons. Cellular senescence is a state in which the cell stays metabolically active but loses the ability to proliferate in response to growth factor. Cell cycle arrest usually occurs upon activation of cell cycle kinase inhibitors such as p21 or p16 [59]. Treatment with Gro1 resulted in marked induction of the senescence marker SA- $\beta$ gal in hippocampal NPC, along with decreased Ki67 and induced p16 indicating decreased cell proliferation. DCX and Tuj-1 were both suppressed, showing a decrease in neuron development, while $\mathrm{Ng} 2$, a marker of oligodendrocytes, was elevated. 
These findings were buttressed by our immunocytochemistry results showing that the number of proliferating Ki67+/Tuj-1+ neuroblasts was decreased following Gro1 treatment while the number of proliferating Ki67 +/Ng2+ oligodendrocyte progenitors was increased.

Treatment of HT-22 hippocampal neurons with Gro1 led to very similar results. With this cell line, we also found reduced DCX and Tuj-1 expression, as well as induction of SA- $\beta$ gal, and a marked increase in the number of senescence neurons. Our results are supported by others showing that chemokine signaling via the Gro1 receptor CXCR2 in human fibroblasts reinforces senescence [60]. We further confirmed that Gro1 may limit the proliferation of progenitors of neuronal lineage via senescence by demonstrating reduced SA- $\beta$ gal as well as markedly upregulated DCX expression in Gro1-suppressed murine NPC indicative of increased numbers of neuroblasts. Concordant with our previous observations, PDGF $\alpha$ R was downregulated in cells where Gro1 was low. Senescence is accompanied by a decrease in apoptosis [56, 59, 61], and we found that Gro1 suppressed cleaved caspase 3 expression in both murine NPC and HT-22 cells. At the same time, oligodendrocyte progenitor markers were increased, in agreement with the findings that Gro1 increases proliferation and survival of oligodendrocytes [42-44, 62]. Together, these results indicate that Gro1 induced in response to inflammation shifts hippocampal neurogenesis toward oligodendrocytes, suppressing new neuron development.

Senescent cells secrete the full array of chemokines, cytokines, and growth factors, a phenomenon termed senescence-associated secretome (SAS) [63-65]. In multiple cell types, Gro1 appears to be a part of SAS [54, 63, 66]. Some of these secretome factors may actually enhance the senescence phenotype [59, 65], as evidenced by Gro1 induction of senescence in cancer-associated fibroblasts via an autocrine loop [67]. Our data suggest that Gro1 induced in response to inflammation may trigger senescence in neuronal stem cells or neuroblasts, but not in astrocytes or oligodendrocytes. Further studies are required to unravel these cell-specific Gro1 effects.

Further, our in vivo results show that Grol overexpression in the hippocampus of newborn mice also results in decreased DCX expression. In the newborn brain, expression of SA- $\beta$ gal in Gro1-treated mice was undetectable, while p16 was upregulated. As the marker of oligodendrocyte progenitors PDGF $\alpha$ R was increased, it is likely that this cell cycle arrest was specific to neuroblast proliferation.

LPS treatment evokes strong systemic inflammation in a sequence of events, including blood-brain barrier leakage [68], massive peripheral immune cells infiltration [69], and neuroinflammation. Proinflammatory cytokines are released in the periphery, and cytokines such as
IL-1 $\beta$, TNF- $\alpha$, and IL- 6 are induced in the hippocampus in microglia and astrocytes [18]. Cytokines have been linked to detrimental effects on neurogenesis [17-19, 23], and we and others [31] show that proinflammatory cytokines stimulate Gro1 expression. We demonstrate here that IL-1 $\beta$ is markedly induced in the hippocampus in response to inflammation. Sustained IL- $1 \beta$ expression also results in infiltration of neutrophils and macrophages, and the presence of immune cells is coincident with upregulation of Gro1 in the hippocampus [70]. Therefore, in the course of inflammation, Gro1 may be released from all these multiple sources [71, 72].

Following LPS treatment, we found significantly induced GrOol(Gro1) in the male hippocampus and a blunted response in females. This may be attributed to the blunted IL- $1 \beta$ response to LPS, which we observed both in female mice and in male mice treated with E2.

The hippocampus contains estrogen receptors ER $\alpha$ and ER $\beta$ [73, 74], and hippocampal NPC also express both receptors [75]. Estrogen has been shown to exert a dual effect on Gro1. E2 suppresses Gro1 expression in rodent models at inflammatory sites limiting LPSinduced recruitment of neutrophils, thus limiting Gro1 delivery to the hippocampus [76]. In addition, during acute inflammation, estrogens have been shown to decrease Gro1 expression by enhancing the production and limiting the degradation of the NFKB inhibitor nuclear factor of kappa light polypeptide gene enhancer in

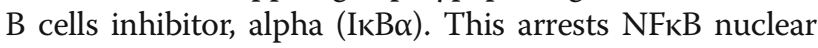
translocation and suppresses Gro1 transcription [76, 77].

Our results suggest that during inflammation, E2, by dampening Gro1 response, may, to some extent, protect female neurogenesis from detrimental acute intense inflammatory stimuli. Sexual dimorphism in Gro1 response to inflammation may therefore be contingent on the level of E2 in females.

A number of limitations should be considered. First, the mechanisms underlying cell-specific effects of Gro1 in NPC, with induced p16 in neuroblasts but suppressed expression in glial progenitors, remain unknown. Second, we tested the effects of LPS on hippocampal Gro1 expression in males and females but did not evaluate how the stage of the estrus cycle in females might further influence outcomes. Third, E2 pellets were implanted in males with intact levels of testosterone, a hormone that can also have protective effects on neurogenesis. Nevertheless, despite these limitations, this study broadens our knowledge and opens new approaches for understanding mechanisms underlying new neuron development in the adult brain.

\section{Conclusions}

We present the first direct evidence that the chemokine Gro1 activates senescence in hippocampal neuronal 
lineage and demonstrate sex-dependent effects of systemic inflammation on Gro1 and subsequent changes in adult hippocampal neurogenesis. The selective vulnerability of hippocampal neurogenesis to inflammation further underscores the need to understand the mechanisms underlying the effects of inflammation and sex dimorphism on the development of new neurons.

\section{Abbreviations}

bFGF: Basic fibroblast growth factor; DAPI: 4',6-Diamidino-2-phenylindole; DCX: Doublecortin; DMEM: Dulbecco's modified Eagle medium; ECL: Enhanced chemiluminescence; EGF: Epidermal growth factor; EGFP: Enhanced green fluorescent protein; FBS: Fetal bovine serum; FGF2: Fibroblast growth factor 2; GAPDH: Glyceraldehyde-3-phosphate dehydrogenase; GDNF: Glial cell-derived neurotrophic factor; GFAP: Glial fibrillary acidic protein; Iba1: Ionized calcium-binding adapter molecule 1; IkBa: Nuclear factor of kappa light polypeptide gene enhancer in B cells inhibitor alpha; NeuN: Neuronal nuclear antigen; NFkB: Nuclear factor kappa-light-chainenhancer of activated B cells; Ng2: Neural glial antigen 2; Olig1,2: Oligodendrocyte transcription factor 1 and 2; PBS: Phosphate-buffered saline; PDGFaR: Plateletderived growth factor a receptor; PSA-NCAM: Polysialylated-neural cell adhesion molecule; PVDF: Polyvinylidene difluoride; RIPA: Radioimmunoprecipitation assay; S100ß: S100 calcium-binding protein B; SA- $\beta$-gal: Senescence-associated $\beta$ galactosidase; SEM: Standard error of the mean; Sox2: Sex-determining region Y-box 2; TBST: Tris-buffered saline; Tuj-1: Neuron-specific class III beta-tubulin

\section{Acknowledgements}

We wish to thank Ms. Shira Berman for the assistance with the manuscript preparation.

\section{Funding}

This study was supported by the UCLA Claude Pepper Older American Independence Center funded by the National Institute of Aging (5P30AG028748) and NIH/NCATS UCLA CTSI (UL1TR000124), and the Iris Cantor-UCLA Women's Health Center Executive Advisory Board (to VC) and NIH 1R33CA202900 and ACS RSG-16-217-01TBG (to JB). The funding sources had no role in the design of the study; in the collection, analysis, and interpretation of data; and in writing the manuscript.

\section{Availability of data and materials}

The data that support the findings of this study are available from the corresponding authors upon reasonable request.

\section{Authors' contributions \\ VC and SZ designed the study, analyzed the results, and performed the pellet implantation and LPS injections. SZ and NG performed the Western blot, real- time PCR, immunohistochemistry, and immunocytochemistry. JB created the plasmids and performed NPC nucleofection and in vivo electroporation. AM provided human surgical specimens and consultation. KW prepared the slides and performed confocal imaging. CB statistically analyzed the data. VC wrote the manuscript. All authors read and approved the final manuscript.}

\section{Ethics approval and consent to participate}

Human surgical specimens were obtained under a protocol approved by the Institutional Review Board at Cedars-Sinai Medical Center. Animal experiments were carried out in strict accordance with the recommendations in the Guide for the Care and Use of Laboratory Animals of the National Institutes of Health The protocol was approved by the Institutional Animal Care and Use Committee at Cedars-Sinai Medical Center.

\section{Consent for publication}

Not applicable.

\section{Competing interests}

The authors declare that they have no competing interests.

\section{Publisher's Note}

Springer Nature remains neutral with regard to jurisdictional claims in published maps and institutional affiliations.

\section{Author details}

${ }^{1}$ Pituitary Center, Department of Medicine, Cedars-Sinai Medical Center, 8700 Beverly Blvd., Los Angeles, CA 90048, USA. ²Department of Neurosurgery, Cedars-Sinai Medical Center, 8700 Beverly Blvd., Los Angeles, CA 90048, USA. ${ }^{3}$ Department of Biomedical Science, Cedars-Sinai Medical Center, 8700 Beverly Blvd., Los Angeles, CA 90048, USA. ${ }^{4}$ Biostatistics and Bioinformatics Core, Cedars-Sinai Medical Center, 8700 Beverly Blvd., Los Angeles, CA 90048, USA.

Received: 2 May 2018 Accepted: 29 August 2018

Published online: 11 September 2018

\section{References}

1. Kempermann G, Gast D, Kronenberg G, Yamaguchi M, Gage FH. Early determination and long-term persistence of adult-generated new neurons in the hippocampus of mice. Development. 2003;130:391-9.

2. Zhao C, Deng W, Gage FH. Mechanisms and functional implications of adult neurogenesis. Cell. 2008;132:645-60.

3. Encinas JM, Vazquez ME, Switzer RC, Chamberland DW, Nick H, Levine HG, Scarpa PJ, Enikolopov G, Steindler DA. Quiescent adult neural stem cells are exceptionally sensitive to cosmic radiation. Exp Neurol. 2008;210:274-9.

4. Encinas JM, Michurina TV, Peunova N, Park JH, Tordo J, Peterson DA, Fishell G, Koulakov A, Enikolopov G. Division-coupled astrocytic differentiation and age-related depletion of neural stem cells in the adult hippocampus. Cell Stem Cell. 2011;8:566-79.

5. Abrous DN, Koehl M, Le Moal M. Adult neurogenesis: from precursors to network and physiology. Physiol Rev. 2005;85:523-69.

6. Nishiyama A, Komitova M, Suzuki R, Zhu X. Polydendrocytes (NG2 cells): multifunctional cells with lineage plasticity. Nat Rev Neurosci. 2009:10:9-22.

7. Bannerman DM, Sprengel R, Sanderson DJ, McHugh SB, Rawlins JN, Monyer $\mathrm{H}$, Seeburg PH. Hippocampal synaptic plasticity, spatial memory and anxiety. Nat Rev Neurosci. 2014;15:181-92

8. Kang $\mathrm{E}$, Wen Z, Song H, Christian KM, Ming GL. Adult neurogenesis and psychiatric disorders. Cold Spring Harb Perspect Biol. 2016;8(9). https://doi. org/10.1101/cshperspect.a019026.

9. Abrous DN, Wojtowicz JM. Interaction between neurogenesis and hippocampal memory system: new vistas. Cold Spring Harb Perspect Biol. 2015;7(6). https://doi.org/10.1101/cshperspect.a018952.

10. Spalding KL, Bergmann O, Alkass K, Bernard S, Salehpour M, Huttner HB, Bostrom E, Westerlund I, Vial C, Buchholz BA, Possnert G, Mash DC, Druid H, Frisen J. Dynamics of hippocampal neurogenesis in adult humans. Cell. 2013:153:1219-27.

11. Eriksson PS, Perfilieva E, Bjork-Eriksson T, Alborn AM, Nordborg C, Peterson DA, Gage FH. Neurogenesis in the adult human hippocampus. Nat Med. 1998:4:1313-7.

12. Gould E, Reeves AJ, Fallah M, Tanapat P, Gross CG, Fuchs E. Hippocampal neurogenesis in adult Old World primates. Proc Natl Acad Sci U S A. 1999; 96:5263-7.

13. Boldrini M, Fulmore CA, Tartt AN, Simeon LR, Pavlova I, Poposka V, Rosoklija GB, Stankov A, Arango V, Dwork AJ, Hen R, Mann JJ. Human hippocampal neurogenesis persists throughout aging. Cell Stem Cell. 2018:22:589-99. e585

14. Coras R, Siebzehnrubl FA, Pauli E, Huttner HB, Njunting M, Kobow K, Villmann C, Hahnen E, Neuhuber W, Weigel D, Buchfelder M, Stefan H, Beck $\mathrm{H}$, Steindler DA, Blumcke I. Low proliferation and differentiation capacities of adult hippocampal stem cells correlate with memory dysfunction in humans. Brain. 2010:133:3359-72.

15. Encinas JM, Vaahtokari A, Enikolopov G. Fluoxetine targets early progenitor cells in the adult brain. Proc Natl Acad Sci U S A. 2006:103:8233-8.

16. Boldrini M, Underwood MD, Hen R, Rosoklija GB, Dwork AJ, John Mann J, Arango $\mathrm{V}$. Antidepressants increase neural progenitor cells in the human hippocampus. Neuropsychopharmacology. 2009;34:2376-89.

17. Ekdahl CT, Kokaia Z, Lindvall O. Brain inflammation and adult neurogenesis: the dual role of microglia. Neuroscience. 2009;158:1021-9.

18. Kohman RA, Rhodes JS. Neurogenesis, inflammation and behavior. Brain Behav Immun. 2013;27:22-32. 
19. Chesnokova V, Pechnick RN, Wawrowsky K. Chronic peripheral inflammation, hippocampal neurogenesis, and behavior. Brain Behav Immun. 2016:58:1-8.

20. Schafer DP, Stevens B. Microglia function in central nervous system development and plasticity. Cold Spring Harb Perspect Biol. 2015;7:a020545.

21. Monje ML, Toda H, Palmer TD. Inflammatory blockade restores adult hippocampal neurogenesis. Science. 2003;302:1760-5.

22. Zonis S, Ljubimov VA, Mahgerefteh M, Pechnick RN, Wawrowsky K Chesnokova V. p21Cip restrains hippocampal neurogenesis and protects neuronal progenitors from apoptosis during acute systemic inflammation. Hippocampus. 2013;23:1383-94.

23. Borsini A, Zunszain PA, Thuret S, Pariante CM. The role of inflammatory cytokines as key modulators of neurogenesis. Trends Neurosci. 2015;38:145-57.

24. Belnoue L, Grosjean N, Abrous DN, Koehl M. A critical time window for the recruitment of bulbar newborn neurons by olfactory discrimination learning. J Neurosci. 2011;31:1010-6.

25. Belmadani A, Tran PB, Ren D, Miller RJ. Chemokines regulate the migration of neural progenitors to sites of neuroinflammation. J Neurosci. 2006;26: 3182-91.

26. Wolpe SD, Davatelis G, Sherry B, Beutler B, Hesse DG, Nguyen HT, Moldawer LL, Nathan CF, Lowry SF, Cerami A. Macrophages secrete a novel heparinbinding protein with inflammatory and neutrophil chemokinetic properties. J Exp Med. 1988;167:570-81.

27. Johnson EA, Dao TL, Guignet MA, Geddes CE, Koemeter-Cox Al, Kan RK. Increased expression of the chemokines CXCL1 and MIP-1alpha by resident brain cells precedes neutrophil infiltration in the brain following prolonged soman-induced status epilepticus in rats. J Neuroinflammation. 2011;8:41.

28. Thompson $W L$, Van Eldik LJ. Inflammatory cytokines stimulate the chemokines CCL2/MCP-1 and CCL7/MCP-3 through NFkB and MAPK dependent pathways in rat astrocytes [corrected]. Brain Res. 2009;1287: 47-57.

29. An Y, Chen Q, Quan N. Interleukin-1 exerts distinct actions on different cell types of the brain in vitro. J Inflamm Res. 2011;2011:11-20.

30. Choi K, Ni L, Jonakait GM. Fas ligation and tumor necrosis factor alpha activation of murine astrocytes promote heat shock factor- 1 activation and heat shock protein expression leading to chemokine induction and cell survival. J Neurochem. 2011;116:438-48.

31. Hennessy E, Griffin EW, Cunningham C. Astrocytes are primed by chronic neurodegeneration to produce exaggerated chemokine and cell infiltration responses to acute stimulation with the cytokines IL-1beta and TNF-alpha. J Neurosci. 2015;35:8411-22.

32. Roy M, Richard JF, Dumas A, Vallieres L. CXCL1 can be regulated by IL-6 and promotes granulocyte adhesion to brain capillaries during bacterial toxin exposure and encephalomyelitis. J Neuroinflammation. 2012;9:18.

33. Warford J, Lamport AC, Kennedy B, Easton AS. Human brain chemokine and cytokine expression in sepsis: a report of three cases. Can J Neurol Sci. 2017; 44:96-104.

34. Kim JM, Oh YK, Lee JH, Im DY, Kim YJ, Youn J, Lee CH, Son H, Lee YS, Park $J Y$, Choi IH. Induction of proinflammatory mediators requires activation of the TRAF, NIK, IKK and NF-kappaB signal transduction pathway in astrocytes infected with Escherichia coli. Clin Exp Immunol. 2005;140:450-60.

35. Turbic A, Leong SY, Turnley AM. Chemokines and inflammatory mediators interact to regulate adult murine neural precursor cell proliferation, survival and differentiation. PLoS One. 2011;6:e25406.

36. Listwak SJ, Rathore P, Herkenham M. Minimal NF-kappaB activity in neurons. Neuroscience. 2013;250:282-99

37. Burke SJ, Lu D, Sparer TE, Masi T, Goff MR, Karlstad MD, Collier JJ. NF-kappaB and STAT1 control CXCL1 and CXCL2 gene transcription. Am J Physiol Endocrinol Metab. 2014;306:E131-49.

38. Amiri $\mathrm{Kl}$, Richmond $\mathrm{A}$. Fine tuning the transcriptional regulation of the CXCL1 chemokine. Prog Nucleic Acid Res Mol Biol. 2003;74:1-36.

39. Charo IF, Ransohoff RM. The many roles of chemokines and chemokine receptors in inflammation. N Engl J Med. 2006;354:610-21.

40. Semple BD, Bye N, Rancan M, Ziebell JM, Morganti-Kossmann MC. Role of CCL2 (MCP-1) in traumatic brain injury (TBI): evidence from severe TBI patients and CCL2-/- mice. J Cereb Blood Flow Metab. 2010;30:769-82.

41. Calver AR, Hall AC, Yu WP, Walsh FS, Heath JK, Betsholtz C, Richardson WD. Oligodendrocyte population dynamics and the role of PDGF in vivo. Neuron. 1998;20:869-82.

42. Tsai HH, Frost $\mathrm{E}$, To V, Robinson $\mathrm{S}$, Ffrench-Constant C, Geertman R, Ransohoff RM, Miller RH. The chemokine receptor CXCR2 controls positioning of oligodendrocyte precursors in developing spinal cord by arresting their migration. Cell. 2002;110:373-83.

43. Robinson S, Franic LA. Chemokine GRO1 and the spatial and temporal regulation of oligodendrocyte precursor proliferation. Dev Neurosci. 2001;23: 338-45.

44. Filipovic R, Zecevic N. The effect of CXCL1 on human fetal oligodendrocyte progenitor cells. Glia. 2008;56:1-15.

45. Breunig JJ, Levy R, Antonuk CD, Molina J, Dutra-Clarke M, Park H, Akhtar AA, Kim GB, Hu X, Bannykh SI, Verhaak RG, Danielpour M. Ets factors regulate neural stem cell depletion and gliogenesis in ras pathway glioma. Cell Rep. 2015;12:258-71.

46. Park TI, Monzo H, Mee EW, Bergin PS, Teoh HH, Montgomery JM, Faull RL, Curtis MA, Dragunow M. Adult human brain neural progenitor cells (NPCs) and fibroblast-like cells have similar properties in vitro but only NPCs differentiate into neurons. PLoS One. 2012;7:e37742.

47. van Strien ME, Sluijs JA, Reynolds BA, Steindler DA, Aronica E, Hol EM. Isolation of neural progenitor cells from the human adult subventricular zone based on expression of the cell surface marker CD271. Stem Cells Transl Med. 2014:3:470-80.

48. Roy NS, Wang S, Jiang L, Kang J, Benraiss A, Harrison-Restelli C, Fraser RA, Couldwell WT, Kawaguchi A, Okano H, Nedergaard M, Goldman SA. In vitro neurogenesis by progenitor cells isolated from the adult human hippocampus. Nat Med. 2000;6:271-7.

49. Doetsch F. The glial identity of neural stem cells. Nat Neurosci. 2003;6:1127-34.

50. Pechnick RN, Zonis S, Wawrowsky K, Pourmorady J, Chesnokova V. p21Cip1 restricts neuronal proliferation in the subgranular zone of the dentate gyrus of the hippocampus. Proc Natl Acad Sci U S A. 2008;105:1358-63.

51. Davis JB, Maher P. Protein kinase $C$ activation inhibits glutamate-induced cytotoxicity in a neuronal cell line. Brain Res. 1994;652:169-73.

52. Morimoto BH, Koshland DE Jr. Induction and expression of long- and shortterm neurosecretory potentiation in a neural cell line. Neuron. 1990;5:875-80.

53. Paxinos G, Franklin K. The mouse brain in stereotaxic coordinates. 4th Edition. Elsevier; 2012.

54. Lesina M, Wormann SM, Morton J, Diakopoulos KN, Korneeva O, Wimmer M Einwachter H, Sperveslage J, Demir IE, Kehl T, Saur D, Sipos B, Heikenwalder M, Steiner JM, Wang TC, Sansom OJ, Schmid RM, Algul H. RelA regulates CXCL1/ CXCR2-dependent oncogene-induced senescence in murine Kras-driven pancreatic carcinogenesis. J Clin Invest. 2016;126:2919-32.

55. Dimri GP, Lee X, Basile G, Acosta M, Scott G, Roskelley C, Medrano EE, Linskens M, Rubelj I, Pereira-Smith $\mathrm{O}$, et al. A biomarker that identifies senescent human cells in culture and in aging skin in vivo. Proc Natl Acad Sci U S A. 1995;92:9363-7.

56. Campisi J. Cellular senescence and apoptosis: how cellular responses might influence aging phenotypes. Exp Gerontol. 2003:38:5-11.

57. Offner $\mathrm{H}$, Adlard K, Zamora A, Vandenbark AA. Estrogen potentiates treatment with $T$-cell receptor protein of female mice with experimental encephalomyelitis. J Clin Invest. 2000;105:1465-72.

58. Freeman ME, Kanyicska B, Lerant A, Nagy G. Prolactin: structure, function, and regulation of secretion. Physiol Rev. 2000;80:1523-631.

59. Munoz-Espin D, Serrano M. Cellular senescence: from physiology to pathology. Nat Rev Mol Cell Biol. 2014;15:482-96.

60. Acosta JC, O'Loghlen A, Banito A, Guijarro MV, Augert A, Raguz S, Fumagalli M, Da Costa M, Brown C, Popov N, Takatsu Y, Melamed J, d'Adda di Fagagna F, Bernard D, Hernando E, Gil J. Chemokine signaling via the CXCR2 receptor reinforces senescence. Cell. 2008;133:1006-18.

61. Sharpless NE, DePinho RA. Telomeres, stem cells, senescence, and cancer. J Clin Invest. 2004;113:160-8.

62. Hosking MP, Tirotta E, Ransohoff RM, Lane TE. CXCR2 signaling protects oligodendrocytes and restricts demyelination in a mouse model of viralinduced demyelination. PLoS One. 2010;5:e11340.

63. Demaria M, O'Leary MN, Chang J, Shao L, Liu S, Alimirah F, Koenig K, Le C, Mitin N, Deal AM, Alston S, Academia EC, Kilmarx S, Valdovinos A, Wang B, de Bruin A, Kennedy BK, Melov S, Zhou D, Sharpless NE, Muss H, Campisi J. Cellular senescence promotes adverse effects of chemotherapy and cancer relapse. Cancer Discov. 2017;7:165-76.

64. Tchkonia T, Zhu Y, van Deursen J, Campisi J, Kirkland JL. Cellular senescence and the senescent secretory phenotype: therapeutic opportunities. J Clin Invest. 2013:123:966-72.

65. Coppe JP, Desprez PY, Krtolica A, Campisi J. The senescence-associated secretory phenotype: the dark side of tumor suppression. Annu Rev Pathol. 2010;5:99-118. 
66. Yang G, Rosen DG, Zhang Z, Bast RC Jr, Mills GB, Colacino JA, MercadoUribe I, Liu J. The chemokine growth-regulated oncogene 1 (Gro-1) links RAS signaling to the senescence of stromal fibroblasts and ovarian tumorigenesis. Proc Natl Acad Sci U S A. 2006;103:16472-7.

67. Kim EK, Moon S, Kim DK, Zhang X, Kim J. CXCL1 induces senescence of cancer-associated fibroblasts via autocrine loops in oral squamous cell carcinoma. PLoS One. 2018;13:e0188847.

68. Banks WA, Gray AM, Erickson MA, Salameh TS, Damodarasamy M, Sheibani N, Meabon JS, Wing EE, Morofuji Y, Cook DG, Reed MJ. Lipopolysaccharideinduced blood-brain barrier disruption: roles of cyclooxygenase, oxidative stress, neuroinflammation, and elements of the neurovascular unit. J Neuroinflammation. 2015;12:223.

69. He H, Geng T, Chen P, Wang M, Hu J, Kang L, Song W, Tang H. NK cells promote neutrophil recruitment in the brain during sepsis-induced neuroinflammation. Sci Rep. 2016:6:27711.

70. Shaftel SS, Carlson TJ, Olschowka JA, Kyrkanides S, Matousek SB, O'Banion MK. Chronic interleukin-1 beta expression in mouse brain leads to leukocyte infiltration and neutrophil-independent blood brain barrier permeability without overt neurodegeneration. J Neurosci. 2007;27:9301-9.

71. Valles A, Grijpink-Ongering L, de Bree FM, Tuinstra T, Ronken E. Differential regulation of the CXCR2 chemokine network in rat brain trauma: implications for neuroimmune interactions and neuronal survival. Neurobiol Dis. 2006;22:312-22.

72. Semple BD, Kossmann T, Morganti-Kossmann MC. Role of chemokines in CNS health and pathology: a focus on the CCL2/CCR2 and CXCL8/CXCR2 networks. J Cereb Blood Flow Metab. 2010;30:459-73.

73. Shima N, Yamaguchi Y, Yuri K. Distribution of estrogen receptor beta mRNA-containing cells in ovariectomized and estrogen-treated female rat brain. Anat Sci Int. 2003;78:85-97.

74. Mahmoud R, Wainwright SR, Galea LA. Sex hormones and adult hippocampal neurogenesis: regulation, implications, and potential mechanisms. Front Neuroendocrinol. 2016;41:129-52.

75. Mazzucco CA, Lieblich SE, Bingham BI, Williamson MA, Viau V, Galea LA. Both estrogen receptor alpha and estrogen receptor beta agonists enhance cell proliferation in the dentate gyrus of adult female rats. Neuroscience. 2006;141:1793-800.

76. Nadkarni S, McArthur S. Oestrogen and immunomodulation: new mechanisms that impact on peripheral and central immunity. Curr Opin Pharmacol. 2013;13:576-81.

77. Xing D, Oparil S, Yu H, Gong K, Feng W, Black J, Chen YF, Nozell S. Estrogen modulates NFkappaB signaling by enhancing IkappaBalpha levels and blocking p65 binding at the promoters of inflammatory genes via estrogen receptor-beta. PLoS One. 2012;7:e36890

Ready to submit your research? Choose BMC and benefit from:

- fast, convenient online submission

- thorough peer review by experienced researchers in your field

- rapid publication on acceptance

- support for research data, including large and complex data types

- gold Open Access which fosters wider collaboration and increased citations

- maximum visibility for your research: over $100 \mathrm{M}$ website views per year

At BMC, research is always in progress.

Learn more biomedcentral.com/submissions 